OPEN ACCESS

Edited by:

David Reser,

Monash University, Australia

Reviewed by:

Akiya Watakabe,

RIKEN Center for Brain Science

(CBS), Japan

Bruno Cozzi,

University of Padova, Italy

Lisette J. A. Kogelman,

University of Copenhagen, Denmark

${ }^{*}$ Correspondence:

Leon French

leonfrench@gmail.com

Received: 26 April 2019

Accepted: 31 October 2019

Published: 27 November 2019

Citation:

Ibrahim C, Le Foll B and French L

(2019) Transcriptomic

Characterization of the Human Insular

Cortex and Claustrum

Front. Neuroanat. 13:94

doi: 10.3389/fnana.2019.00094

\section{Transcriptomic Characterization of the Human Insular Cortex and Claustrum}

\author{
Christine Ibrahim ${ }^{1,2}$, Bernard Le Foll1,2,3,4,5,6,7 and Leon French ${ }^{4,6,7,8 *}$ \\ 1 Translational Addiction Research Laboratory, Centre for Addiction and Mental Health, Toronto, ON, Canada, ${ }^{2}$ Department \\ of Pharmacology and Toxicology, University of Toronto, Toronto, ON, Canada, ${ }^{3}$ Addictions Division, Centre for Addiction \\ and Mental Health, Toronto, ON, Canada, ${ }^{4}$ Institute of Medical Science, University of Toronto, Toronto, ON, Canada, \\ ${ }^{5}$ Department of Family and Community Medicine, University of Toronto, Toronto, ON, Canada, ${ }^{6}$ Division of Brain \\ and Therapeutics, Department of Psychiatry, University of Toronto, Toronto, ON, Canada, ${ }^{7}$ Campbell Family Mental Health \\ Research Institute, Centre for Addiction and Mental Health, Toronto, ON, Canada, ${ }^{8}$ Krembil Centre for Neuroinformatics, \\ Centre for Addiction and Mental Health, Toronto, ON, Canada
}

The insular cortex has been linked to a multitude of functions. In contrast, the nearby claustrum is a densely connected subcortical region with unclear function. To view the insula-claustrum region from the molecular perspective we analyzed the transcriptomic profile of these areas in six adult and four fetal human brains. We identified marker genes with specific expression and performed transcriptomewide tests for enrichment of biological processes, molecular functions, and cellular components. In addition, specific insular and claustral expression of genes pertaining to diseases, addiction, and depression was tested. At the anatomical level, we used brain-wide analyses to determine the specificity of our results and to determine the transcriptomic similarity of the insula-claustrum region. We found UCMA to be the most significantly enriched gene in the insular cortex and confirmed specific expression of NR4A2, NTNG2, and LXN in the claustrum. Furthermore, the insula was found to have enriched expression of genes associated with mood disorders, learning, cardiac muscle contraction, oxygen transport, glutamate and dopamine signaling. Specific expression in the claustrum was enriched for genes pertaining to human immunodeficiency virus (HIV), severe intellectual disability, epileptic encephalopathy, intracellular transport, spine development, and macroautophagy. We tested for enrichment of genes related to addiction and depression, but they were generally not highly specific to the insulaclaustrum region. Exceptions include high insular expression of genes linked to cocaine abuse and genes associated with ever smoking in the claustrum. Brain-wide, we find that markers of the adult claustrum are most specifically expressed in the fetal and adult insula. Altogether, our results provide a novel molecular perspective on the unique properties of the insula and claustrum.

Keywords: transcriptomics, insula, claustrum, addiction, depression, epilepsy, dopamine, macroautophagy 


\section{INTRODUCTION}

The insular cortex (IC), part of the cerebral cortex, is commonly divided into anterior and posterior parts which differ in functional connectivity, as well as in cytoarchitecture (Mesulam and Mufson, 1982; Deen et al., 2011; Kelly et al., 2012). It is also subdivided into subregions known as granular, dysgranular, and agranular (Paxinos and Watson, 1986). The former terminology is commonly used when referring to the human IC, while the latter is used in rodents. The insula as a whole has major bidirectional connections to several regions such as the anterior cingulate cortex, orbitofrontal cortex, supplementary motor areas, amygdala, etc. (Augustine, 1996; Flynn, 1999). Along with these connections, the IC has a multitude of functions, most notably its involvement in conscious urges, homeostasis, interoception, decision making, anxiety and cognition (Craig, 2002; Paulus and Stein, 2006; Chang et al., 2013; Droutman et al., 2015a).

The claustrum, whose name means "hidden away," is a thin bilateral brain region made of gray matter that is embedded in the white matter beneath the IC and above the putamen (Crick and Koch, 2005). By volume, it is the most heavily connected structure in the brain (Torgerson et al., 2015). Mouse tract tracing studies have found that it is connected to almost every region in the cortex (Wang et al., 2017). However, due to its small size and location, its functional roles are not entirely understood. It has been postulated that the claustrum is an integral area for bringing together information within and across sensory and motor modalities to form one joint experience in consciousness (Crick and Koch, 2005).

The establishment of atlases that assay genome-wide gene expression in the human brain by the Allen Institute for Brain Science and their collaborators allows for in-depth analysis of over 200 regions. These comprehensive atlases include the long and short insular gyrus (i.e., posterior and anterior IC, respectively) and the claustrum (Hawrylycz et al., 2012; Miller et al., 2014a). To date, gene expression studies in these regions have been limited in the number of genes investigated and to rodent brains (D'Souza et al., 2008; Mathur et al., 2009; Dillingham et al., 2017; Wang et al., 2017). An exception is a four-gene study that examined the monkey claustrum to find neocortical similarities (Watakabe et al., 2014). A detailed analysis of the transcriptomic profile of the insula and claustrum in the human brain would be of value to further solidify what is known of these areas, as well as to provide new insights.

In this study, using human transcriptomic data, we identified genes with specific expression in the adult and fetal IC and claustrum. In addition, we also tested if genes associated with particular functions and diseases are uniquely expressed in these neighboring regions. Given past associations of these regions, we undertook addiction and depression focused analyses (Naqvi and Bechara, 2010; Sliz and Hayley, 2012; Bernstein et al., 2016; Gogolla, 2017). Due to the neurodevelopmental links of these adjacent regions, we compared their transcriptomic profiles to determine overlapping patterns (Puelles, 2014; Watson and Puelles, 2017; Binks et al., 2019).

\section{MATERIALS AND METHODS}

Broady, we extended methods that have been previously used for the characterization of the habenula (Le Foll and French, 2018).

\section{Adult Human Brain Gene Expression Data}

Transcriptomic data that comprehensively assays the adult human brain was obtained from the Allen Human Brain Atlas (Hawrylycz et al., 2012). All six brains assayed in the Atlas contained insular gyri and claustrum samples (five males one female; aged 24 to 57 years old). As documented by the Allen Institute, postmortem blood was tested for the presence of therapeutic drugs and drugs with abuse potential. Caffeine (all 6 donors), theobromine (3 donors), atropine (3 donors), lidocaine (1 donor), monoethylglycinexylidide (1 donor), and ibuprofen (1 donor) were detected at levels that are not considered toxicologically significant. The Allen Institute also assayed RNA integrity (RIN), which, across the six brains, ranged from 6.3 to 7.5 in the frontal poles, $5.8-7.1$ occipital poles, $6.9-8.6$ in the cerebellum, and 5.6-7.3 in the brainstem. In total, 3,702 spatially resolved gene expression profiles were used, providing expression information for 232 unique named brain regions. The 58,692 microarray probes were filtered to the 48,170 that mapped to the 20,778 gene symbols in the Allen annotations. Details of the procedures used by the Allen Institute researchers to annotate and normalize the data are available at the Allen Human Brain Atlas website ${ }^{1}$.

\section{Prenatal Human Gene Expression Data}

We additionally used the transcriptomic atlas for the normal mid-gestational human brain that was created by the BrainSpan consortium (Miller et al., 2014a). As noted by Brainspan Consortium, RIN values averaged 6.3. The dorsal claustrum, dysgranular and granular IC were acquired in all four of the prenatal specimens used for this atlas (15-21 postconception weeks, 3 females and one male). The ventral claustrum was assayed in three of the specimens ( 1 male and 2 females). The specimens passed several exclusion criteria and no neuropathological defects were found by the consortium. Data from the four specimens contained 1,203 spatially resolved gene expression samples, providing transcriptomic data for 516 unique named brain regions. The same custom microarrays that were used for the adult atlas were used to profile expression. Details of the procedures used by the Allen Institute researchers are available at the BrainSpan website ${ }^{2}$.

\section{Region-Specific Expression Analysis}

Mirroring our previous work that targeted the habenula (Le Foll and French, 2018), we used the limma software package to detect probes that are specifically expressed in the claustrum and insula (Ritchie et al., 2015). In the adult data, those regions are: claustrum, short insular gyri, and long insular gyri. In the fetal brain, we used data from the agranular IC (area Iag),

\footnotetext{
${ }^{1}$ http://help.brain-map.org/display/humanbrain/Documentation

${ }^{2} \mathrm{http}: / /$ help.brain-map.org/display/devhumanbrain/Documentation
} 
dysgranular IC, granular IC, dorsal claustrum, and ventral claustrum. Data from the dorsal and ventral claustrum were combined to form a single claustrum grouping for comparison with the adult data. Two samples from the agranular IC (area Iag) were grouped with the dysgranular IC to simplify analysis. Unlike the adult dataset, the fetal data has fine dissections of cortical zones and layers. We grouped these finer samples into their enclosing cortical regions. This grouping reduces the 516 unique named brain regions in the fetal data to 283 . For each microarray probe, linear models were fit with coefficients for donor and region of interest. In other words, expression of a given probe across the expression measurements (adult:3,702, fetal:1,203) was modeled with variables indicating the donor and if the sampled region was the specific region of interest or not. Separate analyses were undertaken for each region of interest instead of fitting a linear model with coefficients for every brain region. The empirical Bayes moderation method implemented in limma was used to calculate moderated $t$ statistics and corresponding $p$-values (Ritchie et al., 2015). We used the Benjamini-Hochberg false discovery rate (FDR) procedure to correct for the many tested probes (Benjamini and Hochberg, 1995). To summarize the probe level statistics, we used the probe to gene mappings provided by the Allen Institute for the fetal data (Hawrylycz et al., 2012; Miller et al., 2014b). For a given gene, we summarized the region-specific expression results by choosing the probe with the lowest $p$-value to represent the gene. The threshold for significance was set to $p_{\mathrm{FDR}}<0.05$ at the probe level and then applied to the minimum $p$-values at the gene level.

\section{Gene Set Enrichment Analysis}

For a given region of interest, $p$-values were combined with the direction of effect for the 20,778 genes (signed $p$-values). The resulting ranking starts with the gene with the most significant specific expression to the gene with the most significant depleted expression in the region. This ranking allowed us to test if the genes that were specifically expressed in the claustrum or insula are enriched for a given gene set using the area under the receiver operator curve (AUROC) statistic. The AUROC for a set of genes is equivalent to the probability that a gene associated with that set will be found first in the genome-wide ranking compared to all other genes. In this context, AUROC $>0.5$ for a gene set means that these genes are more likely to have higher expression in a region of interest. In contrast, an AUROC $<0.5$ marks a bias toward lower expression. Given our focus on up-regulation, we only tested for AUROC values above 0.5. AUROC values were calculated with the tmod analysis package in R (Weiner and Domaszewska, 2016). The Mann-Whitney $U$ test was used to determine statistical significance (one-sided). We again used the FDR procedure to adjust for the many tested gene sets.

We also use specificity tests to determine if the enriched gene sets are not representing broad differences that are up-regulated in many other brain regions. For example, insula specific gene sets may simply represent neocortex specific expression. To assess specificity, we ran the region-specific expression and gene set enrichment procedures for 283 fetal and 232 named brain regions in the expression datasets. For each gene set, we counted the number of regions with an AUROC value higher than the region of interest. Gene sets that have the highest specificity were considered to characterize the region of interest uniquely.

\section{Gene Ontology Gene Sets}

The Gene Ontology (GO) consortium annotates genes to biological processes, molecular functions, and cellular locations to formally model biological systems using controlled vocabularies (Ashburner et al., 2000). The GO database was accessed through the GO.db and org.Hs.eg.db packages in $\mathrm{R}$ (Carlson, 2017a,b). Annotations were dated October 10, 2018. We limited our tests to GO groups containing between 10 and 200 genes, after filtering for genes contained in the Allen microarray data (7,089 GO groups annotating 15,017 genes).

\section{Estimation of Cell-Type Proportions}

The markerGeneProfile $\mathrm{R}$ package was used to estimate cell type proportions from the transcriptomic data (Ogan et al., 2017). This method uses the first principal component obtained from a set of cell-type specific markers to estimate the relative abundance of a cell type. For cell-type markers, we used genes from a study of healthy human temporal cortex tissue (Darmanis et al., 2015). This study provided the top 21 most enriched genes for astrocytes, neurons, oligodendrocytes, oligodendrocyte precursors, microglia and endothelial celltypes [Supplementary Table S3; (Darmanis et al., 2015)]. The default parameters for the mgpEstimate function were used. Proportions were estimated separately for each donor brain. Within a brain, proportions were mean averaged across multiple samples for each brain region. Regional proportions for each cell-type were then scaled and then mean averaged across the brains. Ranks were then computed across all regions for each cell-type to provide relative rankings of estimated proportions.

\section{Disease-Associated Gene Sets}

Human disease-associated gene sets were obtained from the DisGeNET database, which integrates disease-gene links from several sources (Piñero et al., 2017). The curated gene-disease association file was downloaded in May 2018. Similar to the GO sets, we used disease-associated gene sets with 10 to 200 genes (1,848 disease-associated gene sets covering 5,865 unique genes). The gene set named "severe mental retardation (I.Q. 20-34)" was renamed to "severe intellectual disability (I.Q. 20-34)" to reflect newer terminology.

To complement the heterogeneous data that is used to build the DisGeNET, we used genes from large genetic studies focused on addiction or depression. For lifetime cannabis use associations, we used the seven genes harboring the genomewide significant loci from Table 1 in Pasman et al. (2018). Nine genes near the 14 genome-wide loci associated with alcohol consumption were obtained from Clarke et al. (2017). Genes associated with several smoking-related measures were identified in Minicã et al. (2017). Four genes linked to substance use disorder and five associated with opioid use disorder were 
obtained from a review of genetic studies by Jensen (2016). For depression, we used the 70 genes that neighbor the 44 significant loci identified in the largest genetic study of major depression to date [Table 2 in Wray et al. (2018)]. We also used a more recent list of 269 genes from a large study of depression [Supplementary Table S9 in Howard et al. (2019)].

\section{Transcriptomic Similarities Between the Claustral and Insular Regions}

Complete expression profiles (58,692 probes) were clustered into two dimensional space with the Uniform Manifold Approximation and Projection (UMAP) method (McInnes et al., 2018). This general-purpose dimensionality reduction method is built from principles in Riemannian geometry and algebraic topology. The $\mathrm{R}$ implementation was used with default configuration parameters.

We computed the transcriptional similarity between the adult claustrum and all other regions using the AUROC method. To provide a finer resolution, we did not collapse the developing cortical zones. Instead of all genome-wide significant genes, only the top 20 genes for the claustrum were used to provide a specific signal.

\section{RESULTS}

\section{Insular Cortex}

\section{Long Insular Gyri and Granular Insular Cortex}

We first investigated up-regulated expression in the long insular gyri in adult Atlas. In total, there were 48,165 tested microarray probes, which mapped to 20,778 genes. Of these genes, 1,273 were significantly up-regulated in the 22 long insular gyri samples in comparison to the rest of the brain $\left(p_{\mathrm{FDR}}<0.05\right)$. The top 20 genes are presented in Table 1, and the full probe level results are in Supplementary Table S1. We also tested the human fetal brain and found 733 significantly enriched genes in the 19 granular IC samples. At this mid-gestational stage, corticogenesis is well underway as nine zones can be delineated in the developing neocortex (Bystron et al., 2008; Miller et al., 2014a). Overlap was observed between the adult and fetal results with 160 intersecting genes (hypergeometric test, $p<10^{-46}$ ). However, no overlap was found between the top 20 lists, but we note that the majority of genes are driven by more than one probe.

\section{Short Insular Gyri and Dysgranular Insular Cortex}

With regards to the 22 adult short insular gyri samples, 2,697 genes were significantly up-regulated $\left(p_{\text {FDR }}<0.05\right)$. The top 20 genes are shown in Table 2 (probe level results in Supplementary Table S2). In the fetal brain data, there were 881 enriched genes in the 22 dysgranular IC samples. Between the two, there were 407 intersecting genes (hypergeometric test, $p<10^{-134}$ ) and two genes overlap within the top 20 lists (TFAP2D and SLN).

\section{Genes Upregulated Across the Insular Cortex}

In the adult data, many genes had high expression in both the long and short insular gyri. Of the significantly up-regulated
TABLE 1 | Top 20 enriched genes in the adult long insular gyri.

\begin{tabular}{|c|c|c|c|}
\hline $\begin{array}{l}\text { Gene } \\
\text { Symbol }\end{array}$ & Name & $\begin{array}{l}\text { Significant } \\
\text { probes }\end{array}$ & $p$-value \\
\hline UCMA & $\begin{array}{l}\text { Upper zone of growth plate and } \\
\text { cartilage matrix associated }\end{array}$ & 2 & $4.63 E-45$ \\
\hline NAA11 & $\begin{array}{l}\text { N(alpha)-acetyltransferase } 11, \text { NatA } \\
\text { catalytic subunit }\end{array}$ & 1 & $9.89 \mathrm{E}-17$ \\
\hline MMP3 & Matrix metallopeptidase 3 & 2 & $1.2 \mathrm{E}-16$ \\
\hline MUC19 & Mucin 19, oligomeric & 1 & 3.27E-09 \\
\hline NTNG2 & Netrin G2 & 3 & 3.44E-09 \\
\hline DCSTAMP & $\begin{array}{l}\text { Dendrocyte expressed seven } \\
\text { transmembrane protein }\end{array}$ & 1 & 4.99E-09 \\
\hline LAIR2 & $\begin{array}{l}\text { Leukocyte associated immunoglobulin } \\
\text { like receptor } 2\end{array}$ & 2 & 5.28E-09 \\
\hline PGA3 & Pepsinogen 3, group I (pepsinogen A) & 2 & $1.44 \mathrm{E}-08$ \\
\hline SMIM32 & Small integral membrane protein 32 & 2 & 1.68E-08 \\
\hline GYPE & Glycophorin E (MNS blood group) & 1 & $3.42 \mathrm{E}-08$ \\
\hline LOC100129291 & $\begin{array}{l}\text { Chromosome } X \text { open reading frame } 49 \\
\text { pseudogene }\end{array}$ & 2 & 4.32E-08 \\
\hline DUSP13 & Dual specificity phosphatase 13 & 2 & 6.67E-08 \\
\hline TMEM233 & Transmembrane protein 233 & 2 & 7.01E-08 \\
\hline OLFML2B & Olfactomedin like 2B & 1 & 9.83E-08 \\
\hline NPPA & Natriuretic peptide A & 2 & 9.83E-08 \\
\hline LYZL4 & Lysozyme like 4 & 2 & 9.86E-08 \\
\hline FAM217A & $\begin{array}{l}\text { Family with sequence similarity } 217 \\
\text { member A }\end{array}$ & 1 & $1.55 \mathrm{E}-07$ \\
\hline HABP2 & Hyaluronan binding protein 2 & 1 & $1.8 \mathrm{E}-07$ \\
\hline TEPP & Testis, prostate and placenta expressed & 2 & 2.19E-07 \\
\hline ANXA8 & Annexin A8 & 1 & 2.31E-07 \\
\hline
\end{tabular}

genes, 766 intersected between the two subregions of the IC (hypergeometric test, $p<10^{-50}$ ). Within the top 20 gene lists, 8 genes were in common (UCMA, NTNG2, DCSTAMP, LAIR2, PGA3, GYPE, DUSP13, and LYZL4; $\left.p<10^{-19}\right)$. UCMA was the most significantly enriched gene in both regions (Figure 1). In the fetal data, there were 213 genes that are significantly up-regulated in both the granular and dysgranular IC (hypergeometric test, $\left.p<10^{-50}\right)$. Of these, 11 genes were found in both of the top 20 lists (MIR133A1, KIF16B, TMEM244, NR4A2, C1orf115, BHMT, TIPARP, PTPRK, RSPO2, RASGEF1C, and GRP; $\left.p<10^{-29}\right)$.

\section{Gene Ontology Enrichment}

In the adult data, after correcting for multiple comparisons, 252 GO groups were found to be significantly enriched in the long insular gyri and 216 in the short insular gyri (full results in Supplementary Tables S3, S4). With regards to the fetal data, 293 groups were significantly enriched in the dysgranular IC and 90 groups in the granular IC.

We further filtered the results to only include groups that have a higher AUROC statistic in one or no other regions of the 232 tested brain-wide (specificity rank of $\leq 1$ ). With this criterion, 26 GO groups remained in the adult long insular gyri, 7 in the adult short insular gyri, 88 in the fetal dysgranular IC and 4 in the fetal granular IC. Of the 26 groups in the adult long insular gyri that survived the cutoff, 15 are also significantly up-regulated in the 
TABLE 2 | Top 20 enriched genes in the adult short insular gyri.

\begin{tabular}{|c|c|c|c|}
\hline $\begin{array}{l}\text { Gene } \\
\text { Symbol }\end{array}$ & Name & $\begin{array}{l}\text { Significant } \\
\text { probes }\end{array}$ & $p$-value \\
\hline UCMA & $\begin{array}{l}\text { Upper zone of growth plate and } \\
\text { cartilage matrix associated }\end{array}$ & 2 & $3.12 \mathrm{E}-33$ \\
\hline KRT1 & Keratin 1 & 1 & $3.14 \mathrm{E}-17$ \\
\hline LAIR2 & $\begin{array}{l}\text { Leukocyte associated immunoglobulin } \\
\text { like receptor } 2\end{array}$ & 2 & $8.18 \mathrm{E}-16$ \\
\hline GSG1 & Germ cell associated 1 & 1 & $2.1 \mathrm{E}-14$ \\
\hline LYZL4 & Lysozyme like 4 & 2 & 3.27E-14 \\
\hline MS4A8 & Membrane spanning 4-domains A8 & 1 & $2.59 \mathrm{E}-13$ \\
\hline DUSP13 & Dual specificity phosphatase 13 & 2 & $3.19 E-13$ \\
\hline TFAP2D & Transcription factor AP-2 delta & 2 & $4.56 \mathrm{E}-13$ \\
\hline GYPE & Glycophorin E (MNS blood group) & 1 & $3.22 \mathrm{E}-12$ \\
\hline PGA3 & Pepsinogen 3, group I (pepsinogen A) & 2 & $6.13 \mathrm{E}-12$ \\
\hline SMYD1 & SET and MYND domain containing 1 & 2 & $2.89 \mathrm{E}-11$ \\
\hline SCARA5 & Scavenger receptor class A member 5 & 1 & 3.27E-11 \\
\hline DCSTAMP & $\begin{array}{l}\text { Dendrocyte expressed seven } \\
\text { transmembrane protein }\end{array}$ & 2 & $3.92 \mathrm{E}-11$ \\
\hline KLK5 & Kallikrein related peptidase 5 & 2 & 4.35E-11 \\
\hline GYPB & Glycophorin B (MNS blood group) & 1 & 4.73E-11 \\
\hline FREM3 & FRAS1 related extracellular matrix 3 & 2 & $5.69 \mathrm{E}-11$ \\
\hline TWIST2 & Twist family bHLH transcription factor 2 & 1 & $6.21 \mathrm{E}-11$ \\
\hline SLN & Sarcolipin & 2 & $6.73 E-11$ \\
\hline NTNG2 & Netrin G2 & 3 & $7.29 \mathrm{E}-11$ \\
\hline RS1 & Retinoschisin 1 & 2 & $1.13 \mathrm{E}-10$ \\
\hline
\end{tabular}

fetal granular IC $\left(p_{\text {uncorrected }}<0.05\right)$. These GO groups mainly pertain to glutamate activity and oxygen transport (Table 3 and Figure 2). Of the seven groups that survived the cutoff filter in the adult short insular gyri, "dopamine receptor signaling pathway" and "nucleotide-sugar metabolic process" are enriched in the fetal dysgranular IC ( $\left.p_{\text {uncorrected }}<0.05\right)$ (Table 4).

\section{Disease Associated Gene Set Enrichment}

We first tested for enrichment across all 1,848 disease associated gene lists from the DisGeNET database (full results in Supplementary Tables S5, S6). Genes annotated to cocainerelated disorders was the top result in both regions (Figure 3). For the long insular gyri this was the only disease associated set that survives multiple test correction (90 genes, $p_{\mathrm{FDR}}=0.014$, AUROC $=0.63$ ). For this result, five regions have a higher AUROC value for this set (specificity rank $=5$ ). As detailed above, these genes are not enriched in the fetal granular IC but are in both the short insular gyri and the fetal dysgranular IC (Table 5). Genes associated with mood disorders were also significantly enriched in the short insular gyri. No other disease gene sets were significant after correcting for multiple comparisons in the adult data.

\section{Addiction Focused Gene Set Enrichment}

Given past associations between the insula and addiction, we searched disease terms pertaining to addiction. As described above, cocaine-related disorders was the most significantly up-regulated disease association in both the long and short insular gyri. This was also significant in the fetal dysgranular IC (90 genes, $p_{\text {uncorrected }}<0.032$, AUROC $=0.56$, specificity rank $=73$ out of 283 regions). Genes linked to amphetaminerelated disorders were expressed at above average levels in the adult long and short insular gyri (74 genes, $p_{\text {uncorrected }}<0.020$, AUROC $>0.56$, specificity rank $<7$ ), as well as in the fetal granular IC ( $p_{\text {uncorrected }}<0.022$, AUROC $>0.56$, specificity rank $=37)$. Substance-related disorders were also expressed at higher levels in the adult long insular gyri and fetal granular and dysgranular IC (111 genes, $p_{\text {uncorrected }}<0.040$, AUROC $>0.54$, specificity rank $<36$ ). Substance withdrawal syndrome associated genes were enriched in the adult long and short insular gyri (53 genes, $p_{\text {uncorrected }}<10^{-3}$, AUROC $>0.62$, specificity rank $<12$ ). Beyond the cocaine-associated genes, these findings would not survive correction for the 1,848 disease associated gene lists tested and enrichment was not found for terms relating to marijuana, alcohol, or tobacco.

We also examined GO terms pertaining to drugs of abuse. Both the adult long and short insular gyri and the fetal dysgranular and granular IC had enriched expression of genes annotated to the behavioral response to cocaine term (19 genes, $p_{\text {uncorrected }}<0.018$, AUROC $>0.63$, specificity rank < 39). "Response to cocaine" was also enriched in the fetal granular IC (51 genes, $p$ uncorrected $<0.026$, AUROC $=0.58$, specificity rank $=22$ ). In the adult data, "response to morphine" was enriched (32 genes, $p_{\text {uncorrected }}<0.0074$, AUROC $>0.62$, specificity rank $<15)$ in the long and short insular gyri. This enrichment was significant in the short insular gyri when correcting for the number of GO groups tested $\left(p_{\text {FDR }}<0.02\right)$. In the fetal data, "secondary alcohol biosynthetic process" was enriched in the dysgranular and granular IC (69 genes, $p_{\text {uncorrected }}<0.032$, AUROC $>0.56$, specificity rank < 45). "Alcohol binding" was also enriched in the fetal dysgranular IC (79 genes, $p_{\text {uncorrected }}<0.029$, AUROC $=0.56$, specificity rank $=28$ ). No enrichment was found for nicotine associated gene sets.

Next, we tested genes from genome-wide association studies of addiction. These included studies relating to opioids, smoking, alcohol, and cannabis. None were significantly enriched, except for seven genes that are nearby genetic variants that have been associated with cannabis use. These seven are significantly enriched in both the fetal granular ( $p_{\text {uncorrected }}<0.02$, AUROC $=0.73$, specificity rank $=14$ ) and dysgranular IC ( $p_{\text {uncorrected }}<0.01$, AUROC $=0.77$, specificity rank $=6$ ) but not in the adult insula.

\section{Depression Focused Gene Set Enrichment}

In the DisGeNET database, no gene sets relating to depression were significantly enriched in the adult data nor the fetal data. However, genes associated with seasonal affective disorder were enriched in the adult long and short insular gyri (16 genes, $p_{\text {uncorrected }}<0.041$, AUROC $>0.62$, specificity rank < 33). The adult long insular gyri was also enriched for higher expression of genes linked to major affective disorder (21 genes, $p_{\text {uncorrected }}<0.024$, AUROC $=0.63$, specificity rank $=3$ ) and anhedonia (27 genes, $p_{\text {uncorrected }}<0.0041$, AUROC $=0.65$, specificity rank $=7$ ). We also tested genes from genome-wide 


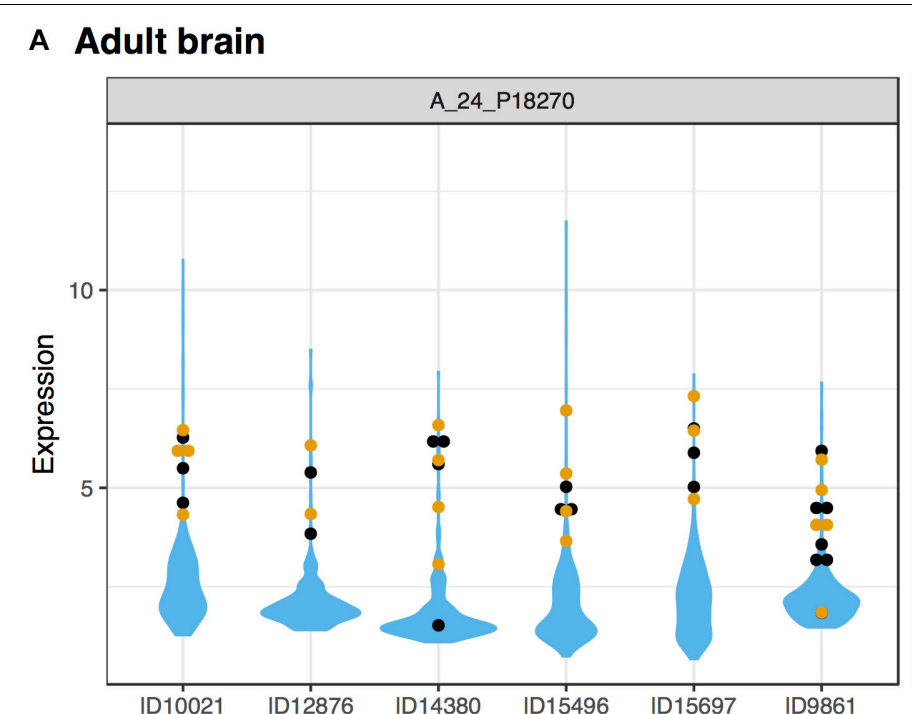

Region

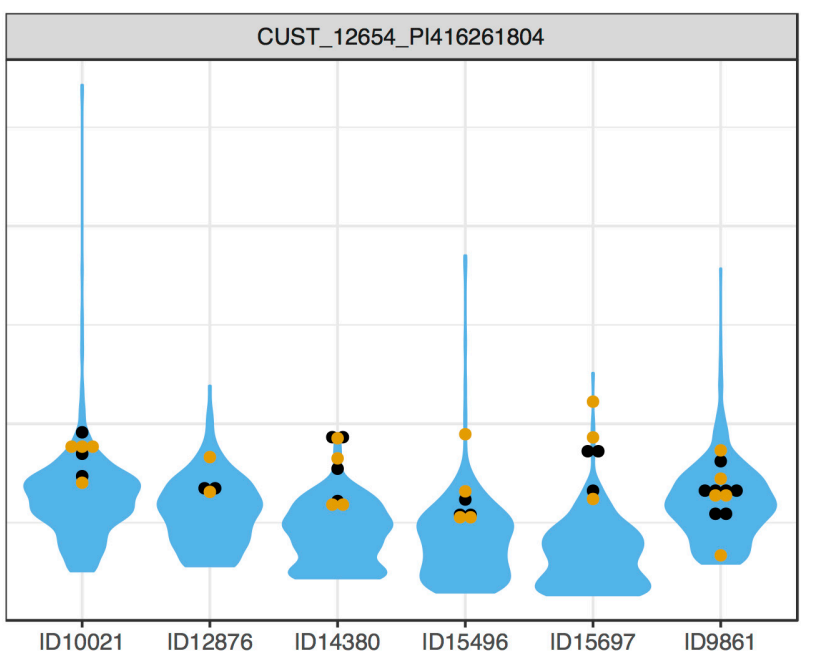

\section{B Fetal brain}
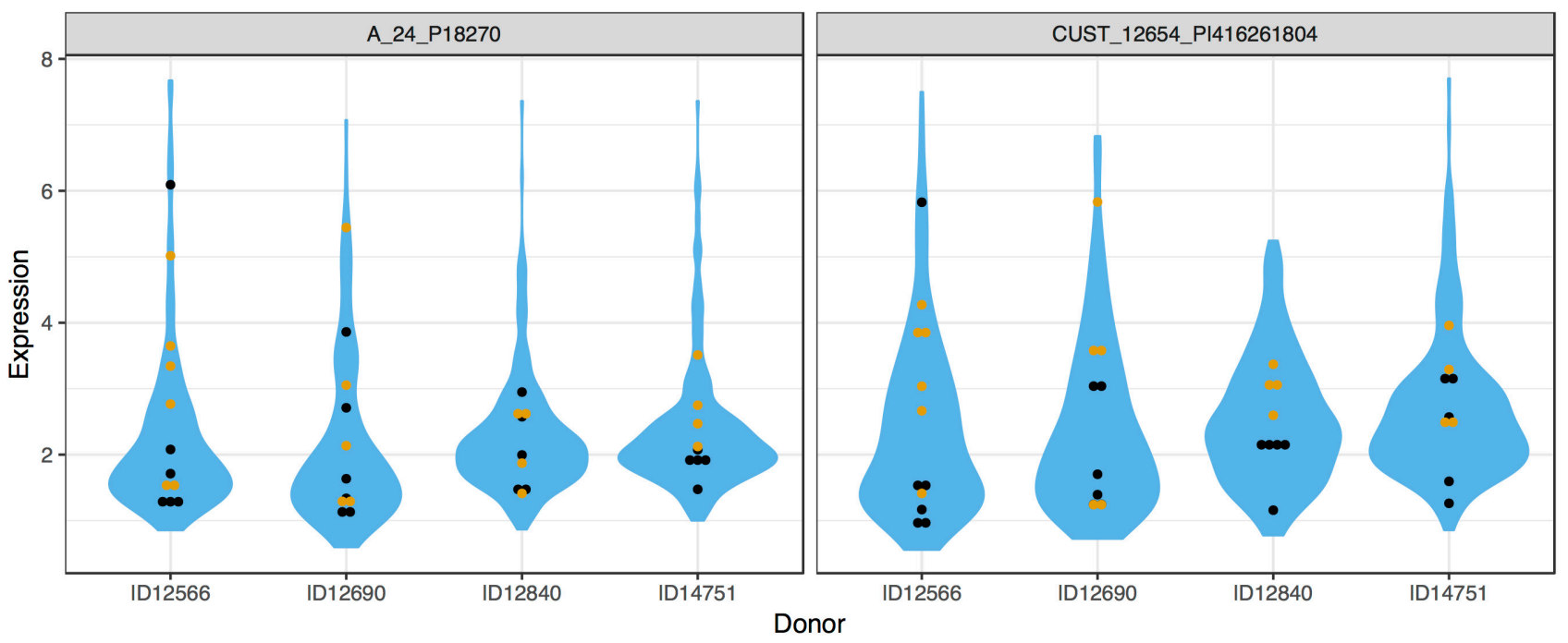

Region

dysgranular insular cortex

granular insular cortex

remaining structures

FIGURE 1 | Plots of UCMA expression in the adult (A) and fetal (B) brains. Expression (log2 intensity) is plotted on the $y$-axis for each of the two probes for UCMA. Donor identification numbers are marked on the $x$-axis. Expression in the short insular gyri and dysgranular insular cortex is marked in black with orange marking the long and granular divisions. Expression across the remaining brain regions is shown in blue violin plots.

association studies of depression. In the adult data, 53 genes associated with major depressive disorder were up-regulated $\left(p_{\text {uncorrected }}<0.037\right.$, AUROC $\left.>0.57\right)$. The 257 genes from the gene based genetic analyses of depression were also enriched in the long insular gyri ( $p_{\text {uncorrected }}<0.030$, AUROC $=0.53$ ). However, we note that this finding was not specific, as over 41 regions had higher AUROC values. In the fetal data, the 53 genes genetically associated with major depressive disorder were specifically enriched in the fetal dysgranular IC (53 genes, puncorrected $<0.003$, AUROC $=0.61$, specificity rank $=3$ ). Overall, we do not observe a clear enrichment of expression for genes associated with depression in the insular region.

\section{Claustrum}

\section{Adult and Fetal Claustrum}

We investigated the genes with significant up-regulation in the adult claustrum. Of the 20,778 tested genes, over $46 \%$ 


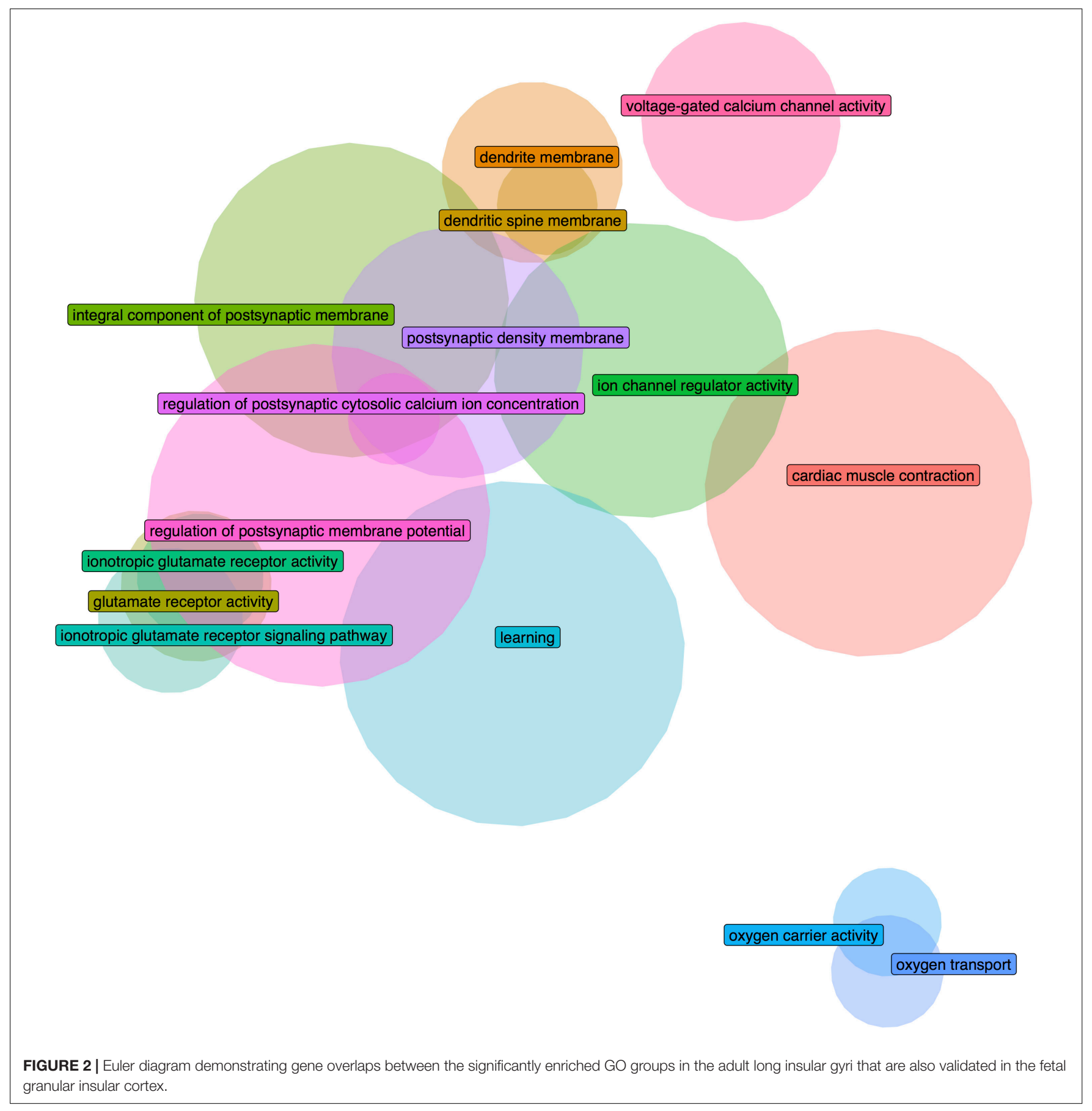

were significantly up-regulated in the 47 claustrum samples $\left(9,591\right.$ genes, $\left.p_{\mathrm{FDR}}<0.05\right)$. The top 20 genes are presented in Table 6 with the full table in Supplementary Table S7. In the seven fetal claustrum samples, only 379 genes were significantly up-regulated $\left(p_{\mathrm{FDR}}<0.05\right)$. Between the adult and fetal data of up-regulated genes, 261 genes intersect (hypergeometric test, $p<10^{-18}$ ), 3 of these are within the top 20 lists (NR4A2, SMIM32, and GNB4). The topranked gene, NR4A2 (ranked 7 th in the fetal data), is plotted in Figure 4.

\section{Gene Ontology Enrichment}

In the adult data, 495 GO groups were significantly enriched after correcting for multiple comparisons and 310 groups in the fetal data $\left(p_{\text {FDR }}<0.05\right.$, full results in Supplementary Table S8). The top result in the adult claustrum was synaptic vesicle cycle with 194 genes $\left(p_{\text {FDR }}<10^{-8}\right.$, AUROC $\left.>0.65\right)$. For the fetal claustrum, the top GO group was intrinsic component of synaptic membrane $\left(166\right.$ genes, $p_{\text {FDR }}<10^{-9}$, AUROC $>0.66$ ).

In addition, we filtered the results to only include groups that have a specificity rank of $\leq 1$. After this cutoff, 159 groups 
TABLE 3 | Enriched GO groups in the adult long insular gyri that are also enriched in the fetal granular insular cortex.

\begin{tabular}{|c|c|c|c|c|c|c|}
\hline Name & Genes & AUROC & Specificity rank & $p$-value FDR $_{1}$ & Fetal AUROC & Fetal $p$-value \\
\hline Integral component of postsynaptic membrane & 117 & 0.712 & 0 & $1.82 \mathrm{E}-12$ & 0.635 & 2.49E-07 \\
\hline Regulation of postsynaptic membrane potential & 139 & 0.688 & 1 & $8.64 \mathrm{E}-12$ & 0.625 & $2.03 E-07$ \\
\hline Postsynaptic density membrane & 75 & 0.729 & 1 & 1.75E-09 & 0.685 & 1.52E-08 \\
\hline Learning & 141 & 0.652 & 1 & $6.13 E-08$ & 0.543 & 0.0389 \\
\hline Ion channel regulator activity & 103 & 0.648 & 1 & $1.53 \mathrm{E}-05$ & 0.599 & $2.59 E-04$ \\
\hline Glutamate receptor activity & 27 & 0.77 & 0 & 6.93E-05 & 0.674 & 8.76E-04 \\
\hline Ionotropic glutamate receptor activity & 19 & 0.799 & 1 & $2.80 \mathrm{E}-04$ & 0.661 & 0.00748 \\
\hline Dendrite membrane & 39 & 0.703 & 1 & 4.68E-04 & 0.635 & 0.00177 \\
\hline lonotropic glutamate receptor signaling pathway & 25 & 0.751 & 0 & 5.37E-04 & 0.623 & 0.0163 \\
\hline Oxygen carrier activity & 14 & 0.764 & 1 & 0.0157 & 0.793 & 7.34E-05 \\
\hline Oxygen transport & 15 & 0.74 & 1 & 0.0246 & 0.788 & $5.64 \mathrm{E}-05$ \\
\hline Cardiac muscle contraction & 127 & 0.583 & 1 & 0.0253 & 0.571 & 0.00302 \\
\hline Voltage-gated calcium channel activity & 47 & 0.631 & 1 & 0.0332 & 0.586 & 0.0203 \\
\hline Regulation of postsynaptic cytosolic calcium ion concentration & 10 & 0.769 & 1 & 0.0481 & 0.719 & 0.00831 \\
\hline Dendritic spine membrane & 12 & 0.743 & 1 & 0.0494 & 0.777 & 4.51E-04 \\
\hline
\end{tabular}

TABLE 4 | Enriched GO groups in the adult short insular gyri that are also enriched in the fetal dysgranular insular cortex.

\begin{tabular}{|c|c|c|c|c|c|c|}
\hline Name & Genes & AUROC & Specificity rank & $p$-value FDR & Fetal AUROC & Fetal $p$-value \\
\hline dopamine receptor signaling pathway & 43 & 0.659 & 1 & 0.00908 & 0.575 & 0.0446 \\
\hline nucleotide-sugar metabolic process & 37 & 0.665 & 1 & 0.0135 & 0.596 & 0.0217 \\
\hline
\end{tabular}

survived in the adult claustrum and 61 groups in the fetal claustrum. Of the 159 significant and specific GO groups in the adult claustrum, 56 were also found in the fetal claustrum ( $p$ uncorrected $<0.05$ ). The top 20 are presented in Table 7 .

\section{Disease Associated Gene Enrichment}

Of the 1,848 disease gene sets from the DisGeNET database, four are significantly up-regulated in the adult claustrum $\left(p_{\text {FDR }}<0.05\right.$, Table 8, full results in Supplementary Table S9). These four are also specific with at most four regions having a higher AUROC value (of 232 regions). Severe intellectual disability (I.Q. 20-34) and epileptic encephalopathy were significantly enriched in both adult and fetal data.

\section{Addiction Focused Gene Set Enrichment}

We examined disease terms relating to addiction using the DisGeNET database. Similar to the insula analyses, in the adult data claustrum, genes associated with "cocaine-related disorders" were enriched (90 genes, $p_{\text {uncorrected }}<0.0072$, AUROC $=0.58$, specificity rank $=79$ out of 232 regions). This was also significant in the fetal data (90 genes, $p_{\text {uncorrected }}<0.0027$, AUROC $=0.59$, specificity rank $=31$ out of 283 regions). Also, in the fetal data, substance withdrawal syndrome (53 genes, $p_{\text {uncorrected }}<0.0021$, AUROC $=0.61$, specificity rank $=26)$, amphetamine-related disorders (74 genes, $p_{\text {uncorrected }}<0.0024$, AUROC $=0.60$, specificity rank $=10$ ), psychoses (substance-induced) (17 genes, $p_{\text {uncorrected }}<0.013$, AUROC $=0.66$, specificity rank $\left.=11\right)$ and alcohol abuse (44 genes, $p_{\text {uncorrected }}<0.044$, AUROC $=0.58$, specificity rank $=87$ ) were enriched. No significant enrichment was found for terms relating to marijuana or tobacco.
GO terms pertaining to drugs of abuse were also searched. In the adult data, response to morphine (32 genes, $p_{\text {uncorrected }}<0.016$, AUROC $=0.61$, specificity rank $=22)$, regulation of alcohol biosynthetic process (73 genes, $p_{\text {uncorrected }}<0.022$, AUROC $=0.57$, specificity rank $=42$ ), and alcohol biosynthetic process (148 genes, $p_{\text {uncorrected }}<0.041$, AUROC $=0.54$, specificity rank $=70$ ) were significantly enriched. While in the fetal data we found behavioral response to cocaine $\left(19\right.$ genes, $p_{\mathrm{FDR}}<0.019$, AUROC $=0.72$, specificity rank $=3$ ) to be significantly enriched after multiple test correction. No significant enrichment was found for terms relating to nicotine.

In addition, three genes genetically associated with ever smoking were enriched in the adult claustrum (BDNF, $A P B B 2$, and CDC27; $p_{\text {uncorrected }}<0.02$, AUROC $=0.84$, specificity rank = 1). In the fetal claustrum, two genes associated with smoking cessation also rank high (SLC25A21 and SEMA6D; $p_{\text {uncorrected }}<0.048$, AUROC $=0.84$, specificity rank $\left.=45\right)$.

\section{Depression Focused Gene Set Enrichment}

Depression associated gene sets in the DisGeNET database were also investigated for significant enrichment in the claustrum. In the adult data, we found seasonal affective disorder to be enriched (16 genes, $p_{\text {uncorrected }}<0.046$, AUROC $=0.62$, specificity rank $=37)$. This was also found in the fetal data ( $p_{\text {uncorrected }}<0.0042$, AUROC $=0.69$, specificity rank $=9$ ). In fetal data, genes annotated to "anhedonia" were significantly enriched, with no other regions having a higher AUROC value (27 genes, $p_{\text {FDR }}<0.048$, AUROC $=0.71$, specificity rank $=0$ ). Also, genes associated with drug-induced depressive state (14 genes, $p_{\text {uncorrected }}<0.033$, AUROC $=0.64$, specificity rank $=27$ ) and depression (bipolar) $\left(12\right.$ genes, $p_{\text {uncorrected }}<0.035$, 
TABLE 5 | Disease gene sets enriched in the adult short insular gyri after multiple test correction.

\begin{tabular}{|c|c|c|c|c|c|c|}
\hline Name & Genes & AUROC & Specificity Rank & $p$-value ${ }_{\mathrm{FDR}}$ & fetal AUROC & fetal $P$-value \\
\hline Cocaine-related disorders & 90 & 0.626 & 14 & 0.0315 & 0.557 & 0.031 \\
\hline Mood disorders & 183 & 0.586 & 5 & 0.0315 & 0.510 & 0.318 \\
\hline
\end{tabular}

not in the fetal samples. Overall, expression of depression associated genes appear to be higher in the claustrum than the insular regions.

\section{Cell Type Proportions}

Based on the adult transcriptomic data and marker genes, we estimated proportions of neurons, oligodendrocytes, oligodendrocyte precursors, microglia and endothelial cell-types (Supplementary Table S10). Relative to all other regions, neurons have the highest relative proportion estimates in the insular-claustrum region. Specifically, only five other regions have a higher estimated amount of neurons, while the short and long insular gyri rank 11th and 28, respectively (of 232 regions). The claustrum also has a high estimated proportion of oligodendrocytes (specificity rank of 49). For the remaining cell-types, we do not observe notable proportion estimates (specificity ranks $<81$ ).

TABLE 6 | Top 20 enriched genes in the adult claustrum.

\begin{tabular}{|c|c|c|c|}
\hline Gene & Name & $\begin{array}{l}\text { Significant } \\
\text { probes }\end{array}$ & $p$-value \\
\hline NR4A2 & $\begin{array}{l}\text { Nuclear receptor subfamily } 4 \text { group A } \\
\text { member } 2\end{array}$ & 3 & 4.98E-209 \\
\hline SLC17A8 & Solute carrier family 17 member 8 & 3 & 1.65E-205 \\
\hline ANXA1 & Annexin A1 & 1 & 8.45E-187 \\
\hline NTNG2 & Netrin G2 & 3 & $2.85 \mathrm{E}-180$ \\
\hline RGS12 & Regulator of $G$ protein signaling 12 & 3 & $2.01 \mathrm{E}-179$ \\
\hline UCMA & $\begin{array}{l}\text { Upper zone of growth plate and cartilage } \\
\text { matrix associated }\end{array}$ & 2 & $3.46 \mathrm{E}-179$ \\
\hline SMIM32 & Small integral membrane protein 32 & 2 & 1.66E-160 \\
\hline STT3B & $\begin{array}{l}\text { STT3B, catalytic subunit of the } \\
\text { oligosaccharyltransferase complex }\end{array}$ & 2 & 1.45E-157 \\
\hline GNB4 & G protein subunit beta 4 & 4 & $5.54 \mathrm{E}-155$ \\
\hline DCSTAMP & $\begin{array}{l}\text { Dendrocyte expressed seven } \\
\text { transmembrane protein }\end{array}$ & 2 & $4.52 E-152$ \\
\hline L1TD1 & $\begin{array}{l}\text { LINE1 type transposase domain containing } \\
1\end{array}$ & 2 & $2.94 \mathrm{E}-148$ \\
\hline GPD2 & Glycerol-3-phosphate dehydrogenase 2 & 2 & $7.76 \mathrm{E}-137$ \\
\hline SMYD1 & SET and MYND domain containing 1 & 2 & $1.61 E-129$ \\
\hline SPATA19 & Spermatogenesis associated 19 & 2 & $2.21 \mathrm{E}-129$ \\
\hline TPMT & Thiopurine S-methyltransferase & 3 & $1.62 \mathrm{E}-125$ \\
\hline THTPA & Thiamine triphosphatase & 2 & 3.07E-121 \\
\hline C1QL4 & Complement C1q like 4 & 1 & $2.40 \mathrm{E}-120$ \\
\hline STK32B & Serine/threonine kinase 32B & 2 & $2.47 \mathrm{E}-120$ \\
\hline LAIR2 & $\begin{array}{l}\text { Leukocyte associated immunoglobulin like } \\
\text { receptor } 2\end{array}$ & 2 & 5.60E-119 \\
\hline PLA2G4A & Phospholipase A2 group IVA & 3 & 4.89E-117 \\
\hline
\end{tabular}

\section{Transcriptomic Similarities Between the Claustral and Insular Regions}

We reduced the dimension of the adult claustral and insular samples to obtain a transcriptome-wide visualization of the similarities between the regions. Using the complete expression profiles, we observe that the claustral samples can be separated from the insular profiles (Figure 5). Within the insula, we do not see a clear grouping of samples from the long and short gyri. While the claustral samples are central in the fetal data, we did not find apparent regional clustering (Supplementary Figure S1).

We next computed the transcriptional similarity between the adult claustrum and all other regions. We calculated which adult and fetal brain regions have enriched expression of the 20 most specific genes in the adult claustrum to determine which brain regions strongly express the adult claustrum markers (Table 9). Brain-wide, insular regions have the highest expression of the adult claustrum marker genes. Of the 232 adult regions tested, 38 are significantly enriched for the marker genes $\left(p_{\text {FDR }}<0.05\right.$, AUROC > 0.5). Of those, 36 are neocortical regions, and the remaining two are the piriform cortex (paleocortex) and parahippocampal gyrus bank of the cos (transitionary). Across all regions, the neocortex is enriched for these marker genes (80 regions, mean AUROC $=0.642$ ). In the adult data, the short gyri is more similar than the long insular gyri. Interestingly, in the fetal results, the claustrum is ranked lower than samples from the insular cortex. The lower absolute AUROC values in the fetal data are likely due to global expression differences between the fetal and adult data. Of the six zones assayed in the insular cortex, the intermediate zone, which is the deepest, has the most specific expression of the 20 claustral markers. We also note that the three-layered piriform cortex has high expression of the markers in both the adult and fetal data. Taken together, we found that the expression of claustral markers is highest in the insula and neocortex.

\section{DISCUSSION}

In this study, we defined the adult and fetal insular cortex and claustrum at the molecular level. We identified gene expression enrichment in these areas concerning diseases, addiction, depression, and function. With regards to the insula, we found genes associated with addiction, most notably cocaine, as well as depression, mood disorders, glutamate and dopamine signaling, learning, memory, cardiac muscle contraction, and oxygen transport. In the claustrum, we found that genes associated with addiction, depression, human immunodeficiency virus (HIV), severe intellectual disability, seizures, epilepsy, intracellular transport, spine development, and macroautophagy 


\section{A Adult brain}

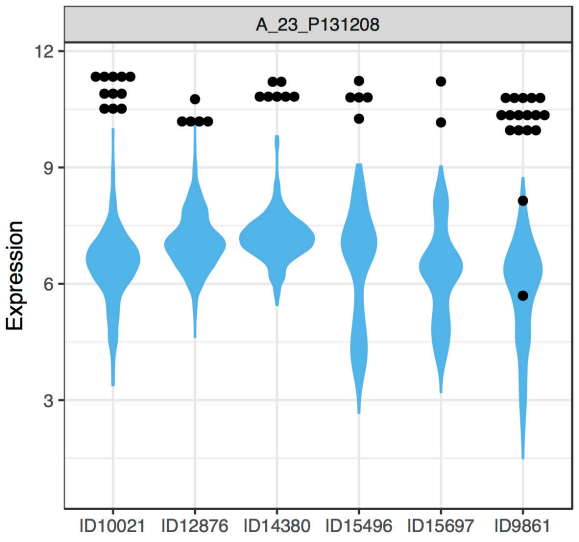

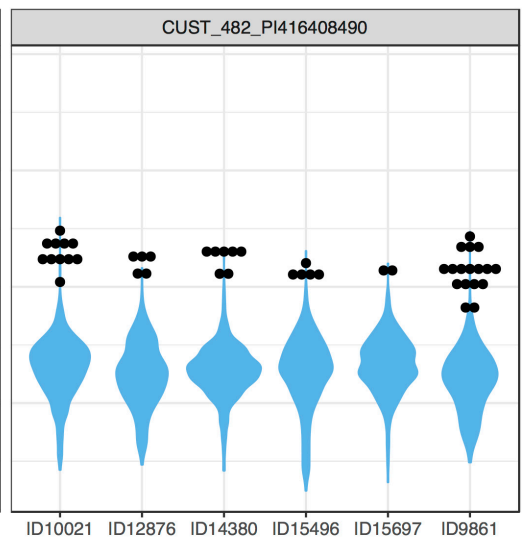

B Fetal brain
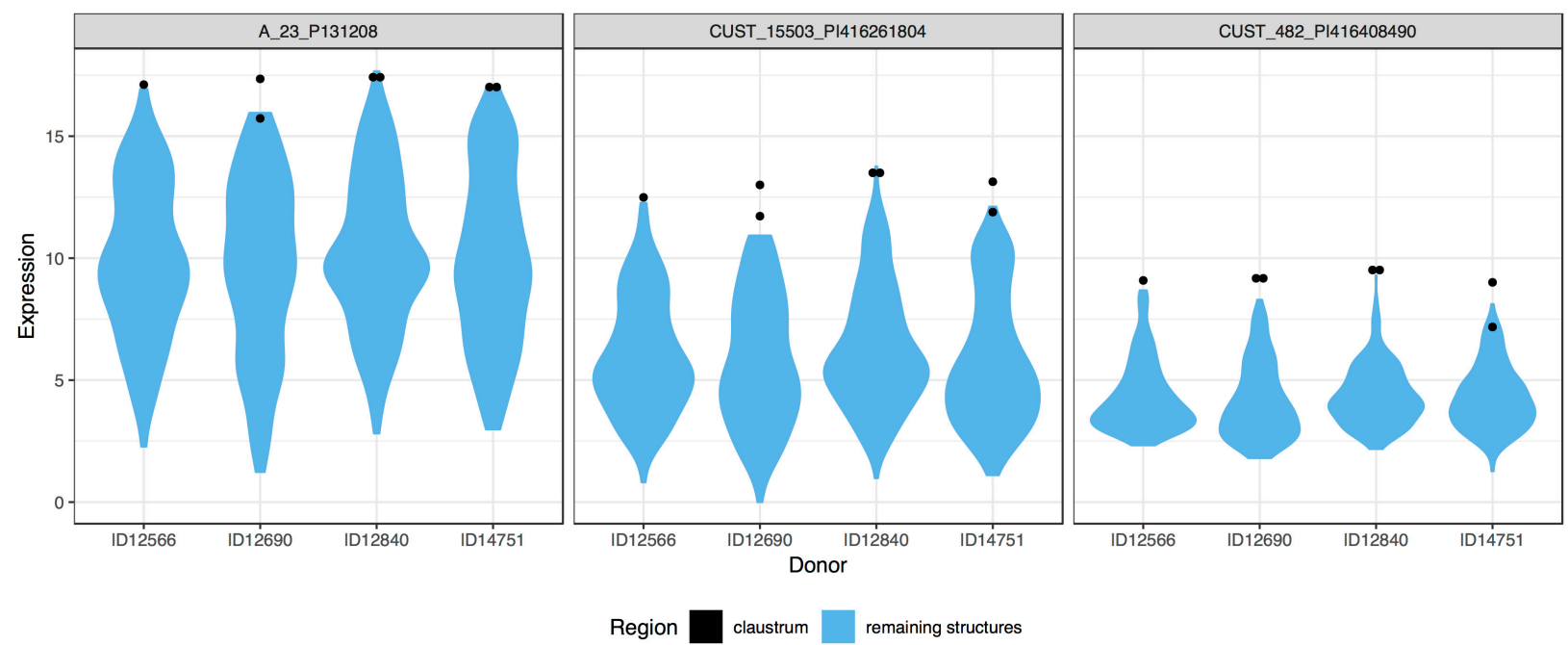

FIGURE 4 | Plots of NR4A2 expression in the adult (A) and fetal (B) brains. Expression (log2 intensity) is plotted on the $y$-axis for each of the three probes for NR4A2. Donor identification numbers are marked on the $x$-axis. Expression in the claustrum is marked in black, expression across the remaining brain regions is shown in blue violin plots.

had enriched expression. Across the brain, we found that the insula has the highest transcriptomic similarity to the claustrum.

\section{Top Ranked Genes}

In terms of individual genes, we found UCMA to be the most significantly enriched gene in the adult long and short insular gyri. It was also present in the adult claustrum (ranked 6th). While its function in the brain is unknown, the UCMA gene has been shown to mark a specific transcriptomic type of layer 5 neurons in a study of the mouse visual and motor cortices (Tasic et al., 2016).

Previous studies have identified specific claustral expression of NR4A2, NTNG2, GNG2, OPRK1, CUX2, and LXN in rodents and primates (Peckys and Landwehrmeyer, 1999; Mathur et al., 2009; Pirone et al., 2012; Watakabe et al., 2014). NR4A2, NTNG2, and $L X N$ are in our top 20 lists and together, these six genes are strongly enriched in the adult and fetal claustrum $(p<0.0005$, AUROC > 0.92). NR4A2 and NTNG2 were also present in the insula's top 20 lists. NR4A2, also known as NURR1, is essential for the differentiation of dopaminergic neurons (Zetterström et al., 1997; Saucedo-Cardenas et al., 1998). It regulates gene expression of numerous factors that are important to the dopamine system; among these are dopamine transporter and tyrosine hydroxylase (Sakurada et al., 1999; Sacchetti et al., 2001). NR4A2 has been implicated in drug addiction (Bannon et al., 2002; Horvath et al., 2007), Parkinson's disease (Jankovic et al., 2005; Le et al., 2008; Zhang et al., 2012), schizophrenia and bipolar disorder (Buervenich et al., 2000; Xing et al., 2006). This is in line with the enrichments we found regarding addiction and depression (bipolar) gene sets in the IC and claustrum, as well as dopamine activity in the IC. Although we did not observe any gene sets indicating an association with Parkinson's disease and schizophrenia, studies have implicated the IC and claustrum in these diseases (Kalaitzakis et al., 2009; Cascella et al., 2011; Chen et al., 2016; Criaud et al., 2016; Arrigo et al., 2018; Joutsa et al., 2018). 
TABLE 7 | Top 20 specifically enriched GO groups in the adult claustrum that are also enriched in the fetal claustrum.

\begin{tabular}{|c|c|c|c|c|c|c|}
\hline Name & Genes & AUROC & Specificity rank & $p$-value FDR & Fetal AUROC & Fetal $p$-value \\
\hline Regulation of macroautophagy & 158 & 0.645 & 0 & 3.57E-07 & 0.623 & $4.48 \mathrm{E}-08$ \\
\hline Cytosolic transport & 151 & 0.641 & 0 & 9.03E-07 & 0.54 & 0.0456 \\
\hline Regulation of dendritic spine development & 65 & 0.694 & 0 & 1.36E-05 & 0.564 & 0.0384 \\
\hline Vacuolar transport & 127 & 0.637 & 1 & 1.98E-05 & 0.614 & 4.46E-06 \\
\hline Regulation of postsynaptic membrane neurotransmitter receptor levels & 65 & 0.688 & 0 & 2.91E-05 & 0.674 & 6.06E-07 \\
\hline Protein serine/threonine phosphatase complex & 48 & 0.712 & 0 & 4.89E-05 & 0.598 & 0.00923 \\
\hline Regulation of phosphatase activity & 170 & 0.613 & 0 & 4.97E-05 & 0.56 & 0.00352 \\
\hline Clathrin-dependent endocytosis & 40 & 0.725 & 0 & $9.02 \mathrm{E}-05$ & 0.692 & $1.28 \mathrm{E}-05$ \\
\hline Cytoskeleton-dependent intracellular transport & 165 & 0.611 & 0 & 9.17E-05 & 0.542 & 0.0308 \\
\hline Regulation of phosphoprotein phosphatase activity & 113 & 0.633 & 0 & 9.17E-05 & 0.582 & 0.00135 \\
\hline Regulation of protein dephosphorylation & 134 & 0.619 & 1 & $1.71 \mathrm{E}-04$ & 0.581 & 6.37E-04 \\
\hline Axo-dendritic transport & 63 & 0.668 & 0 & $2.41 \mathrm{E}-04$ & 0.582 & 0.0119 \\
\hline Autophagosome assembly & 89 & 0.638 & 1 & 3.76E-04 & 0.635 & $5.53 E-06$ \\
\hline Clathrin vesicle coat & 28 & 0.741 & 0 & 4.86E-04 & 0.7 & 1.25E-04 \\
\hline Vesicle coat & 57 & 0.668 & 0 & 5.20E-04 & 0.601 & 0.00409 \\
\hline Organelle transport along microtubule & 74 & 0.646 & 1 & $5.92 \mathrm{E}-04$ & 0.627 & 8.24E-05 \\
\hline Membrane coat & 99 & 0.622 & 1 & 9.25E-04 & 0.617 & $2.88 \mathrm{E}-05$ \\
\hline Clathrin coat of coated pit & 20 & 0.768 & 0 & 0.00117 & 0.712 & $5.28 \mathrm{E}-04$ \\
\hline Vesicle docking & 66 & 0.647 & 0 & 0.00118 & 0.606 & 0.00143 \\
\hline Vesicle-mediated transport to the plasma membrane & 83 & 0.629 & 0 & 0.00143 & 0.6 & 8.44E-04 \\
\hline
\end{tabular}

TABLE 8 | Disease gene sets enriched in the adult claustrum after multiple test correction.

\begin{tabular}{|c|c|c|c|c|c|c|}
\hline Name & Genes & AUROC & Specificity rank & $p$-value FDR & Fetal AUROC & Fetal $P$-value \\
\hline HIV Infections & 99 & 0.633 & 2 & 0.00547 & 0.476 & 0.798 \\
\hline Epileptic encephalopathy & 26 & 0.731 & 3 & 0.0209 & 0.648 & 0.005 \\
\hline Severe intellectual disability (I.Q. 20-34) & 99 & 0.616 & 4 & 0.0237 & 0.628 & $6.16 \mathrm{E}-06$ \\
\hline Global developmental delay, severe & 47 & 0.661 & 2 & 0.0333 & 0.475 & 0.724 \\
\hline
\end{tabular}

\section{Addiction}

Genes associated with cocaine, amphetamine, morphine, alcohol and withdrawal were found to be significant in the IC. Cocaine seems to be the most prominently associated drug of abuse in the insula region as it was the only term that passed multiple test correction. The insula has long been known to play roles in addiction (Droutman et al., 2015b). One of the main studies credited for bringing attention to the insula found that stroke patients that suffered damage to the insula were more likely to quit smoking immediately after lesion onset compared to non-insular damage (Naqvi et al., 2007). Since then, numerous studies have linked the insula with having a prominent role in addictions. Preclinical studies have involved the insula in motivation, nicotine-taking and -seeking behaviors (Forget et al., 2010; Pushparaj et al., 2013), gambling (Pushparaj et al., 2015) and alcohol addiction (Pushparaj and Le Foll, 2015). Numerous clinical studies have also provided valuable information relating the insula and addiction. For instance, cocaine users were found to have decreased gray matter in the insula (Ersche et al., 2011; Gardini and Venneri, 2012), as well as greater connectivity within the salience network (i.e., the anterior IC and anterior cingulate cortex) (Wisner et al., 2013). It was unexpected that no enrichment was found for terms relating to nicotine since many preclinical and clinical studies found insular differences that were associated with nicotine dependence (Droutman et al., 2015b). Given that nicotine triggers the release of dopamine, we note that genes in the dopamine signaling pathway are strongly enriched in the adult and fetal insula, suggesting downstream relationships.

Dopamine is broadly associated with addiction, as all drugs of abuse increase dopamine levels (Nestler, 2005). It has been long known that dopamine is a key player in addiction [see our review (Le Foll et al., 2009)] and is involved in dopamine utilization (Gaspar et al., 1989). Our finding of enriched expression of genes in the dopamine signaling pathway is specific as only one other brain region was found to have a higher AUROC value. Of these 43 genes, dopamine receptors 1 (ranked 5th), 3 (14th), 4 (22nd) and 5 (8th) are ranked in the top half with DRD2 having depleted expression (ranked second last). High expression of $D R D 1$ mirrors previous studies that found higher expression of $D R D 1$ and low expression of DRD2 (Hurd et al., 2001). Functional studies have found insular infusions of a $D_{2}$ antagonist did not have an effect on nicotine self-administration, but a $\mathrm{D}_{1}$ antagonist did (Kutlu et al., 2013). Although it is not as established as dopamine, glutamate has also been shown to play a role in addiction (Tzschentke and Schmidt, 2003; D’Souza, 2015). In the long insular gyri, three gene ontology groups relating to glutamate signaling and activity were enriched, all validated in the fetal data and had high specificity to the insula. Researchers 


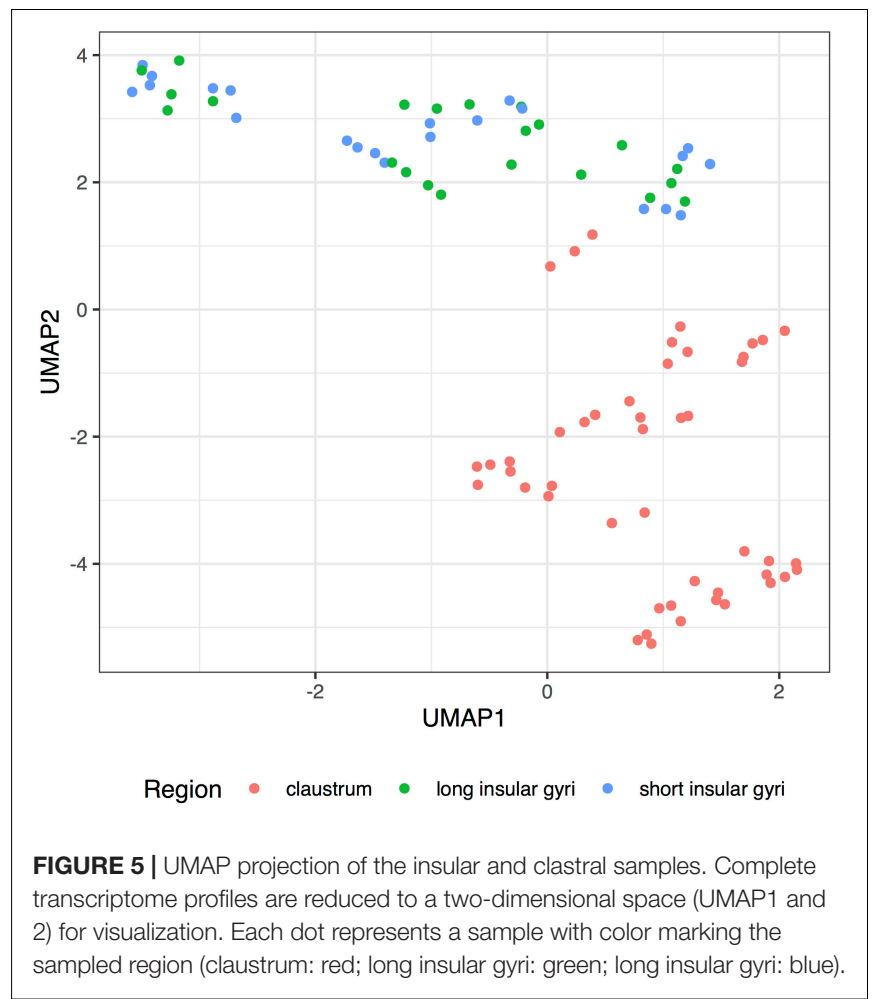

TABLE 9 | The top ten fetal and adult regions that specifically express the 20 most up-regulated genes in the adult claustrum.

\begin{tabular}{|c|c|c|c|c|}
\hline Rank & Adult region & $\begin{array}{l}\text { AUROC } \\
\text { Adult }\end{array}$ & Fetal region & $\begin{array}{l}\text { AUROC } \\
\text { Fetal }\end{array}$ \\
\hline 1 & Claustrum & 1 & $\begin{array}{l}\text { Intermediate zone in granular } \\
\text { insular cortex }\end{array}$ & 0.783 \\
\hline 2 & $\begin{array}{l}\text { Short insular } \\
\text { gyri }\end{array}$ & 0.94 & Layer III of piriform cortex & 0.764 \\
\hline 3 & $\begin{array}{l}\text { Long insular } \\
\text { gyri }\end{array}$ & 0.905 & $\begin{array}{l}\text { Intermediate zone in } \\
\text { dysgranular insular cortex }\end{array}$ & 0.756 \\
\hline 4 & $\begin{array}{l}\text { Frontal } \\
\text { operculum }\end{array}$ & 0.888 & Claustrum & 0.719 \\
\hline 5 & Planum polare & 0.856 & $\begin{array}{l}\text { Subplate zone in dysgranular } \\
\text { insular cortex }\end{array}$ & 0.706 \\
\hline 6 & $\begin{array}{l}\text { Posterior orbital } \\
\text { gyrus }\end{array}$ & 0.842 & $\begin{array}{l}\text { Intermediate zone in primary } \\
\text { auditory cortex }\end{array}$ & 0.703 \\
\hline 7 & $\begin{array}{l}\text { Temporal pole, } \\
\text { inferior aspect }\end{array}$ & 0.842 & Midbrain reticular formation & 0.703 \\
\hline 8 & $\begin{array}{l}\text { Temporal pole, } \\
\text { superior aspect }\end{array}$ & 0.82 & $\begin{array}{l}\text { Molecular layer of caudal } \\
\text { subiculum }\end{array}$ & 0.691 \\
\hline 9 & $\begin{array}{l}\text { Temporal pole, } \\
\text { medial aspect }\end{array}$ & 0.809 & $\begin{array}{l}\text { Subplate zone in caudal } \\
\text { perirhinal cortex }\end{array}$ & 0.687 \\
\hline 10 & Piriform cortex & 0.771 & $\begin{array}{l}\text { Posterior hypothalamic } \\
\text { nucleus }\end{array}$ & 0.673 \\
\hline
\end{tabular}

have demonstrated that glutamate plays a role in drug seeking and reinstatement (Kalivas, 2009; Knackstedt and Kalivas, 2009). Drugs of abuse also alter the transmission of glutamate either by indirectly or directly acting on its receptors (D'Souza, 2015). Clinically, inhibition of glutamate release is a potential target for cocaine addiction treatment (Schmidt and Pierce, 2010; D'Souza, 2015; Caprioli et al., 2018).

\section{Depression}

We find limited evidence of higher expression of depression associated genes in the insula and claustrum. However, genes associated with mood disorders are ranked as the second and third top disease gene sets associated with the adult short and long insular gyri, respectively (specificity $<10$ ). The literature supports the insula and claustrum as having some involvement with depression. Studies have shown that patients with depression have altered functional connectivity in the insula, specifically the anterior region (Veer et al., 2010; Kandilarova et al., 2018; Wang et al., 2018). Gray matter reductions in the anterior insula were also found in patients with major depressive disorder (Lee et al., 2011; Stratmann et al., 2014). A meta-analysis found the insula was consistently identified in imaging studies of depression across methods and study design (Fitzgerald et al., 2008). In comparison to the insula, stronger enrichment of expression for depression associated genes was found in the claustrum. Possibly due to its size and location, the claustrum has not been identified in imaging studies of depression. However, a postmortem study found bilaterally reduced claustral volumes in major depressive disorder (Bernstein et al., 2016). Anhedonia, one of the main symptoms in depression, has been linked to both the insula and claustrum in our results. The most specific depression associated result is the enrichment of "anhedonia" genes in the fetal claustrum. Anhedonia symptoms in individuals with unipolar or bipolar depression were negatively correlated with metabolism in the insula and claustrum (Dunn et al., 2002). Furthermore, in a healthy population of adolescents, those who scored higher on anhedonia measures exhibited decreased activation in the claustrum and insula compared to those who had lower anhedonia scores (Chan et al., 2016). Altogether, we highlight the relevance of this region to mood disorders and anhedonia while suggesting more attention be given to the claustrum.

\section{Learning and Memory}

In the long insular gyri and granular IC, we found a set of 141 genes associated with learning to be significantly and specifically enriched. Although not validated in the fetal data, associative learning was enriched in the adult data. In addition, a memory gene set was enriched in the long insular gyri, with only two other brain regions holding a higher AUROC value. At first glance, the enrichment may be explained by the IC role in taste learning. Studies have indicated its role in working memory of taste (Ragozzino and Kesner, 1999), conditioned taste aversion (Schier et al., 2016) and taste learning [see review by Yiannakas and Rosenblum (2017)]. This is in part mediated by glutamatergic and dopaminergic transmission (Guzmán-Ramos et al., 2010; Osorio-Gómez et al., 2017), which also showed enrichment in the insula. However, no gene ontology groups corresponding to taste specifically were enriched in the IC. Although this was surprising, the insula has been implicated in other areas of learning and memory, which may explain these gene set enrichments. For instance, the insula is activated during a learning/memory task of human face recognition (Paller et al., 2003) and object recognition memory (Bermudez-Rattoni et al., 2005). While the 
long insular gyri has an above average estimated proportion of neurons, the short gyri and claustrum have higher estimates, suggesting this signal is not due to a high proportion of neurons. However, a single-cell dissection of the insula may highlight specific neuron types.

\section{Cardiac Muscle Contraction}

One interesting finding from the gene ontology enrichment in the IC was that of cardiac muscle contraction. We found a gene set of 127 genes relating to cardiac muscle contraction to be significantly and specifically enriched in the long insular gyri. Broadly, the insula has been described as a key region in the brain-heart axis (Nagai et al., 2010). Introception, and specifically awareness of one's heartbeat is among the bodily states that the insula is believed to mediate (Craig, 2002, 2003). This has been shown using heartbeat monitoring tasks whereby researchers have found the insula to be activated (Pollatos et al., 2007; Zaki et al., 2012; Kuehn et al., 2016). These findings are mainly found in the anterior insula. However, the enrichment we observed was in the posterior region. This may be due to the fact that the posterior insula is the receiver of interoceptive signals, which is then sent to the anterior insula (Craig, 2002). Furthermore, damage to the insula was associated with electrocardiographic abnormalities (Abboud et al., 2006) and an increase in adverse cardiac outcomes (e.g., myocardial infarction, new-onset angina, sudden cardiac death) (Laowattana et al., 2006). While these neural connections between the insula and heart are interesting, it's not clear why genes that function in muscle contraction are enriched in the insula.

\section{Oxygen Transport}

We found high and specific enrichment of two oxygen-related GO terms, oxygen transport and oxygen carrier activity, in the adult long insular gyri. This enrichment, was validated in the fetal dysgranular IC as well. It is not known why these genes are enriched here, but we suspect that it could be due to the insula's role in homeostasis. Similarly to the implication of the insula in regulating heartbeat described above, it has also been implicated in regulating breathing and respiration (Kaada and Jasper, 1952; Showers and Lauer, 1961; Hassanpour et al., 2018). In addition, dyspnea (i.e., breathlessness) has been shown to activate the insula (Banzett et al., 2000; von Leupoldt et al., 2008; Esser et al., 2017). However, these studies have found other areas to also be involved; therefore, further studies are needed to clarify why these gene sets were specifically enriched in the insula.

\section{Epilepsy}

Genes associated with seizures and epilepsy were enriched in the claustrum. Specifically, genes linked to epileptic encephalopathy, a severe and early onset disorder are strongly enriched. An example gene is GNAO1, which is the 23rd most specifically expressed gene in the adult claustrum and is known to cause early onset epileptic encephalopathy (Nakamura et al., 2013; Law et al., 2015). Researchers have found that the claustrum was involved early on in kainate-induced seizures and in some instances, the seizure originated in the claustrum (Bayat et al., 2018). A number of studies using magnetic resonance imaging (MRI) have found a link between the claustrum and epilepsy (Sperner et al., 1996; Nixon et al., 2001; Ishii et al., 2011; Meletti et al., 2015, 2017). Although not all seizures affect consciousness, it remains an important feature of seizures (Blumenfeld, 2012). As we previously mentioned, the exact role of the claustrum is not well understood, however, many theories focus around the idea of its involvement in consciousness (Crick and Koch, 2005; Chau et al., 2015; Yin et al., 2016). A case study of an epileptic patient reported that stimulating an electrode placed between the claustrum and anterior IC disrupted consciousness, which was then regained after stimulation stopped (Koubeissi et al., 2014). In fact, the role of the claustrum in consciousness during seizures has been the subject of a recent review (Kurada et al., 2019). Thus, given the enrichment of epilepsy-related genes and the link between consciousness and seizures, this may further allude to the claustrum's role in consciousness.

\section{Human Immunodeficiency Virus}

Genes associated with HIV infections were enriched and had high specificity to the claustrum. In support of this, researchers have found astrogliosis (Sevigny et al., 2005) and increased fractalkine (Tong et al., 2000) in the claustrum of people with HIV encephalitis. Fractalkine is a chemokine encoded by the CX3CL1 gene, which we found to be significantly enriched in both the adult and fetal claustrum. Furthermore, a study on postmortem brains of children who died of acquired immunodeficiency syndrome (AIDS) found the claustrum, among other brain regions, to have a decreased volume (Kozlowski et al., 1997).

\section{Intracellular Transport}

Genes that function in intracellular transport are expressed at higher levels in the claustrum. Specifically enriched GO terms include cytosolic, vacuolar, cytoskeleton-dependent, and axodendritic transport. White matter has long been considered to be a transport system (Paus et al., 2014). Our findings of increased axo-dendritic transport related genes, combined with the region's wide-ranging projections (Torgerson et al., 2015; Wang et al., 2017) suggest that the claustrum may be a key hub in this transport network.

\section{Macroautophagy}

The most specific GO group for the claustrum was "regulation of macroautophagy". We were unable to find any reports in the literature of enhanced macroautophagy or related genes in the claustrum. Given its location in between white matter tracts, we speculate the claustrum may undertake increased macroautophagy based myelin remodeling. Such autophagic mechanisms have shown to be important in the peripheral nerve injury and amyotrophic lateral sclerosis but have not been linked to the claustrum (Ceballos-Diaz et al., 2015; Gomez-Sanchez et al., 2015; Qin et al., 2018). Like the long motor neurons that degenerate in amyotrophic lateral sclerosis, we suspect that a high level of autophagy might be needed to support the connectivity of the claustrum (Torgerson et al., 2015). 


\section{Insula-Claustrum Comparisons}

In a brain-wide analysis, we found that the insula has the highest expression of the claustral markers. More broadly, claustral specific genes are enriched in neocortical regions. Surprisingly, the intermediate zone of the developing insular cortex had higher expression of these genes than the fetal claustrum samples. More specifically, of all the fetal regions, the intermediate zone of the insula had the highest expression of the adult claustral markers. This zone is the deepest of those assayed and thus closest to the insula. The strong expression of adult claustral markers in this zone may inform future developmental studies. Overall, these findings reinforce rodent studies that found the claustrum and insula have a strong ontogenetic relationship through a shared lateral pallium origin (Puelles, 2014; Watson and Puelles, 2017; Binks et al., 2019).

\section{Strengths and Limitations}

This study benefits from two brain- and genome-wide Atlases of the human brain. This coverage allowed us to transfer information from anatomy to genes. By using two transcriptomic Atlases, we were able to test signals obtained from the adult in the fetal brain, providing reproducibility across development. Although this approach reveals novel molecular features of the insula and claustrum, there are some limitations. First, the sample size is limited (six adult brains and four fetal brains). Second, sex is not balanced with five male adult brains and only one female adult brain. The reverse issue is present in the fetal brains, whereby three are female. However, we note that the number of genes differentially expressed across regions dwarfs the number that are sex or even species specific (Strand et al., 2007; Toker et al., 2016). We also note that we use gene expression profiles of bulk tissue, which contain variable proportions of cell-types. Differences in cell-type proportions may be the primary drivers of the extracted signals and not the differential expression of specific genes. At the coarse level, our analysis of estimated celltype proportions did not suggest that our findings are primarily driven primarily by proportion differences.

\section{CONCLUSION}

In conclusion, our study of insular and claustrum specific gene expression links these regions to an array of functions and diseases. Many of these gene enrichments were expected, such as that of genes associated with addiction, as well as some of the top individual genes found in the claustrum, which are known to be claustral markers. Our finding of enrichment of epilepsy gene sets in the claustrum could further allude to its role in consciousness, which has been hypothesized to be its

\section{REFERENCES}

Abboud, H., Berroir, S., Labreuche, J., Orjuela, K., Amarenco, P., and Genic Investigators, (2006). Insular involvement in brain infarction increases risk for cardiac arrhythmia and death. Ann. Neurol. 59, 691-699. doi: 10.1002/ana.20806

Arrigo, A., Calamuneri, A., Milardi, D., Mormina, E., Gaeta, M., Corallo, F., et al.

(2018). Claustral structural connectivity and cognitive impairment in drug primary function. Insular associations with oxygen transport and cardiac muscle contraction molecules reinforce it's past links to interoceptive awareness. Combining the results, we find associations with learning, memory, severe intellectual disability, and epilepsy, suggesting the insula-claustrum region plays critical roles in cognition. Other findings, such as the enrichment of genes involved HIV and macroautophagy in the claustrum require further investigation. In addition, our findings of strong transcriptomic similarity between the two regions confirm their ontogenetic relationship. Altogether, our results provide a novel molecular perspective on the unique properties of the insulaclaustrum region.

\section{DATA AVAILABILITY STATEMENT}

Publicly available datasets were analyzed in this study. This data can be found at http://www.brain-map.org and http://www. brainspan.org.

\section{AUTHOR CONTRIBUTIONS}

BL and LF: conception and design. LF: analysis of data. CI, BL, and LF: interpretation of data. CI: writing the first draft of the manuscript. BL and LF: critical revision of the manuscript.

\section{FUNDING}

This study was supported by the CAMH Foundation and a National Science and Engineering Research Council of Canada (NSERC) Discovery Grant to LF.

\section{ACKNOWLEDGMENTS}

We thank the Allen Institute for Brain Science for creating the Allen Human Brain Atlas. We also thank Derek Howard for help with initial data preparation.

\section{SUPPLEMENTARY MATERIAL}

Scripts, supplementary tables, and data files for reproducing the analyses are available online at https://github.com/leonfrench/ InsulaClaustrumSpecific and https://figshare.com/articles/Trans criptomic_Characterization_of_the_Human_Insular_Cortex_ and_Claustrum/8044727.

naïve Parkinson's disease. Brain Imag. Behav. 13, 933-944. doi: 10.1007/s11682018-9907-z

Ashburner, M., Ball, C. A., Blake, J. A., Botstein, D., Butler, H., Cherry, J. M., et al. (2000). Gene ontology: tool for the unification of biology. Gene. Ontol. Consortium. Nat. Genet. 25, 25-29.

Augustine, J. R. (1996). Circuitry and functional aspects of the insular lobe in primates including humans. Brain 
Res. Brain Res. Rev. 22, 229-244. doi: 10.1016/s0165-0173(96) 00011-2

Bannon, M. J., Pruetz, B., Manning-Bog, A. B., Whitty, C. J., Michelhaugh, S. K., Sacchetti, P., et al. (2002). Decreased expression of the transcription factor NURR1 in dopamine neurons of cocaine abusers. Proc. Natl. Acad. Sci. U.S.A. 99, 6382-6385. doi: 10.1073/pnas.092654299

Banzett, R. B., Mulnier, H. E., Murphy, K., Rosen, S. D., Wise, R. J., and Adams, L. (2000). Breathlessness in humans activates insular cortex. Neuroreport 11, 2117-2120. doi: 10.1097/00001756-200007140-00012

Bayat, A., Joshi, S., Jahan, S., Connell, P., Tsuchiya, K., Chau, D., et al. (2018). A pilot study of the role of the claustrum in attention and seizures in rats. Epilepsy Res. 140, 97-104. doi: 10.1016/j.eplepsyres.2018.01.006

Benjamini, Y., and Hochberg, Y. (1995). Controlling the false discovery rate: a practical and powerful approach to multiple testing. J. R. Stat. Soc. Series B Stat. Methodol. 57, 289-300. doi: 10.1111/j.2517-6161.1995.tb02031.x

Bermudez-Rattoni, F., Okuda, S., Roozendaal, B., and McGaugh, J. L. (2005). Insular cortex is involved in consolidation of object recognition memory. Learn. Mem. 12, 447-449. doi: 10.1101/lm.97605

Bernstein, H.-G., Ortmann, A., Dobrowolny, H., Steiner, J., Brisch, R., Gos, T., et al. (2016). Bilaterally reduced claustral volumes in schizophrenia and major depressive disorder: a morphometric postmortem study. Eur. Arch. Psychiatry Clin. Neurosci. 266, 25-33. doi: 10.1007/s00406-015-0597-x

Binks, D., Watson, C., and Puelles, L. (2019). A Re-evaluation of the anatomy of the claustrum in rodents and primates-analyzing the effect of pallial expansion. Front. Neuroanat. 13:34. doi: 10.3389/fnana.2019.00034

Blumenfeld, H. (2012). Impaired consciousness in epilepsy. Lancet Neurol. 11, 814-826. doi: 10.1016/S1474-4422(12)70188-6

Buervenich, S., Carmine, A., Arvidsson, M., Xiang, F., Zhang, Z., Sydow, O., et al. (2000). NURR1 mutations in cases of schizophrenia and manic-depressive disorder. Am. J. Med. Genet. 96, 808-813. doi: 10.1002/1096-8628(20001204) 96:6<808::aid-ajmg23>3.0.co;2-e

Bystron, I., Blakemore, C., and Rakic, P. (2008). Development of the human cerebral cortex: boulder committee revisited. Nat. Rev. Neurosci. 9, 110-122. doi: $10.1038 / \mathrm{nrn} 2252$

Caprioli, D., Justinova, Z., Venniro, M., and Shaham, Y. (2018). Effect of novel allosteric modulators of metabotropic glutamate receptors on drug selfadministration and relapse: a review of preclinical studies and their clinical implications. Biol. Psychiatry 84, 180-192. doi: 10.1016/j.biopsych.2017.08.018

Carlson, M. (2017a). GO.db: A Set of Annotation Maps Describing the Entire Gene Ontology. Available at:http://bioconductor.org/packages/release/data/ annotation/html/GO.db.html (accessed October 10, 2018).

Carlson, M. (2017b). Org.Hs.eg.db: Genome wide annotation for Human R package Version 3.2.3.

Cascella, N. G., Gerner, G. J., Fieldstone, S. C., Sawa, A., and Schretlen, D. J. (2011). The insula-claustrum region and delusions in schizophrenia. Schizophr. Res. 133, 77-81. doi: 10.1016/j.schres.2011.08.004

Ceballos-Diaz, C., Rosario, A. M., Park, H.-J., Chakrabarty, P., Sacino, A., Cruz, P. E., et al. (2015). Viral expression of ALS-linked ubiquilin-2 mutants causes inclusion pathology and behavioral deficits in mice. Mol. Neurodegener. 10:25. doi: 10.1186/s13024-015-0026-7

Chan, R. C. K., Li, Z., Li, K., Zeng, Y.-W., Xie, W.-Z., Yan, C., et al. (2016). Distinct processing of social and monetary rewards in late adolescents with trait anhedonia. Neuropsychology 30, 274-280. doi: 10.1037/neu0000233

Chang, L. J., Yarkoni, T., Khaw, M. W., and Sanfey, A. G. (2013). Decoding the role of the insula in human cognition: functional parcellation and large-scale reverse inference. Cereb. Cortex 23, 739-749. doi: 10.1093/cercor/ bhs065

Chau, A., Salazar, A. M., Krueger, F., Cristofori, I., and Grafman, J. (2015). The effect of claustrum lesions on human consciousness and recovery of function. Conscious. Cogn. 36, 256-264. doi: 10.1016/j.concog.2015.06.017

Chen, X., Duan, M., He, H., Yang, M., Klugah-Brown, B., Xu, H., et al. (2016). Functional abnormalities of the right posterior insula are related to the altered self-experience in schizophrenia. Psychiatr. Res. Neuroimag. 256, 26-32. doi: 10.1016/j.pscychresns.2016.09.006

Clarke, T.-K., Adams, M. J., Davies, G., Howard, D. M., Hall, L. S., Padmanabhan, S., et al. (2017). Genome-wide association study of alcohol consumption and genetic overlap with other health-related traits in UK Biobank ( $\mathrm{N}=112$ 117). Mol. Psychiatry 22, 1376-1384. doi: 10.1038/mp.2017.153
Craig, A. D. (2002). How do you feel? interoception: the sense of the physiological condition of the body. Nat. Rev. Neurosci. 3, 655-666. doi: 10.1038/nr n894

Craig, A. D. (2003). Interoception: the sense of the physiological condition of the body. Curr. Opin. Neurobiol. 13, 500-505. doi: 10.1016/s0959-4388(03)00 090-4

Criaud, M., Christopher, L., Boulinguez, P., Ballanger, B., Lang, A. E., Cho, S. S., et al. (2016). Contribution of insula in parkinson's disease: a quantitative metaanalysis study. Hum. Brain Mapp. 37, 1375-1392. doi: 10.1002/hbm.23109

Crick, F. C., and Koch, C. (2005). What is the function of the claustrum? Philos. Trans. R. Soc. Lond. B Biol. Sci. 360, 1271-1279. doi: 10.1098/rstb.2005.1661

Darmanis, S., Sloan, S. A., Zhang, Y., Enge, M., Caneda, C., Shuer, L. M., et al. (2015). A survey of human brain transcriptome diversity at the single cell level. Proc. Natl. Acad. Sci. U.S.A. 112, 7285-7290. doi: 10.1073/pnas.1507125112

Deen, B., Pitskel, N. B., and Pelphrey, K. A. (2011). Three systems of insular functional connectivity identified with cluster analysis. Cereb. Cortex 21, 14981506. doi: 10.1093/cercor/bhq186

Dillingham, C. M., Jankowski, M. M., Chandra, R., Frost, B. E., and O’Mara, S. M. (2017). The claustrum: considerations regarding its anatomy, functions and a programme for research. Brain Neurosci. Adv. 1, 1-9.

Droutman, V., Bechara, A., and Read, S. J. (2015a). Roles of the different subregions of the insular cortex in various phases of the decision-making process. Front. Behav. Neurosci. 9:309. doi: 10.3389/fnbeh.2015.00309

Droutman, V., Read, S. J., and Bechara, A. (2015b). Revisiting the role of the insula in addiction. Trends Cogn. Sci. 19, 414-420. doi: 10.1016/j.tics.2015.05.005

D’Souza, C. A., Chopra, V., Varhol, R., Xie, Y.-Y., Bohacec, S., Zhao, Y., et al. (2008). Identification of a set of genes showing regionally enriched expression in the mouse brain. BMC Neurosci. 9:66. doi: 10.1186/1471-2202-9-66

D’Souza, M. S. (2015). Glutamatergic transmission in drug reward: implications for drug addiction. Front. Neurosci. 9:404. doi: 10.3389/fnins.2015.00404

Dunn, R. T., Kimbrell, T. A., Ketter, T. A., Frye, M. A., Willis, M. W., Luckenbaugh, D. A., et al. (2002). Principal components of the beck depression inventory and regional cerebral metabolism in unipolar and bipolar depression. Biol. Psychiatry 51, 387-399. doi: 10.1016/s0006-3223(01)01244-6

Ersche, K. D., Barnes, A., Jones, P. S., Morein-Zamir, S., Robbins, T. W., and Bullmore, E. T. (2011). Abnormal structure of frontostriatal brain systems is associated with aspects of impulsivity and compulsivity in cocaine dependence. Brain 134, 2013-2024. doi: 10.1093/brain/awr138

Esser, R. W., Stoeckel, M. C., Kirsten, A., Watz, H., Taube, K., Lehmann, K., et al. (2017). Brain activation during perception and anticipation of dyspnea in chronic obstructive pulmonary disease. Front. Physiol. 8:617. doi: 10.3389/ fphys.2017.00617

Fitzgerald, P. B., Laird, A. R., Maller, J., and Daskalakis, Z. J. (2008). A metaanalytic study of changes in brain activation in depression. Hum. Brain Mapp. 29, 683-695. doi: 10.1002/hbm.20426

Flynn, F. G. (1999). Anatomy of the insula functional and clinical correlates. Aphasiology 13, 55-78. doi: 10.1080/026870399402325

Forget, B., Pushparaj, A., and Le Foll, B. (2010). Granular insular cortex inactivation as a novel therapeutic strategy for nicotine addiction. Biol. Psychiatry 68, 265-271. doi: 10.1016/j.biopsych.2010.01.029

Gardini, S., and Venneri, A. (2012). Reduced grey matter in the posterior insula as a structural vulnerability or diathesis to addiction. Brain Res. Bull. 87, 205-211. doi: 10.1016/j.brainresbull.2011.11.021

Gaspar, P., Berger, B., Febvret, A., Vigny, A., and Henry, J. P. (1989). Catecholamine innervation of the human cerebral cortex as revealed by comparative immunohistochemistry of tyrosine hydroxylase and dopaminebeta-hydroxylase. J. Comp. Neurol. 279, 249-271. doi: 10.1002/cne.90279 0208

Gogolla, N. (2017). The insular cortex. Curr. Biol. 27, R580-R586. doi: 10.1016/j. cub.2017.05.010

Gomez-Sanchez, J. A., Carty, L., Iruarrizaga-Lejarreta, M., Palomo-Irigoyen, M., Varela-Rey, M., Griffith, M., et al. (2015). Schwann cell autophagy, myelinophagy, initiates myelin clearance from injured nerves. J. Cell Biol. 210, 153-168. doi: 10.1083/jcb.201503019

Guzmán-Ramos, K., Osorio-Gómez, D., Moreno-Castilla, P., and BermúdezRattoni, F. (2010). Off-line concomitant release of dopamine and glutamate involvement in taste memory consolidation. J. Neurochem. 114, 226-236. doi: 10.1111/j.1471-4159.2010.06758.x 
Hassanpour, M. S., Simmons, W. K., Feinstein, J. S., Luo, Q., Lapidus, R. C., Bodurka, J., et al. (2018). The insular cortex dynamically maps changes in cardiorespiratory interoception. Neuropsychopharmacology 43, 426-434. doi: 10.1038/npp.2017.154

Hawrylycz, M. J., Lein, E. S., Guillozet-Bongaarts, A. L., Shen, E. H., Ng, L., Miller, J. A., et al. (2012). An anatomically comprehensive atlas of the adult human brain transcriptome. Nature 489, 391-399. doi: 10.1038/nature11405

Horvath, M. C., Kovacs, G. G., Kovari, V., Majtenyi, K., Hurd, Y. L., and Keller, E. (2007). Heroin abuse is characterized by discrete mesolimbic dopamine and opioid abnormalities and exaggerated nuclear receptor-related 1 transcriptional decline with age. J. Neurosci. 27, 13371-13375. doi: 10.1523/jneurosci.2398-07. 2007

Howard, D. M., Adams, M. J., Clarke, T.-K., Hafferty, J. D., Gibson, J., Shirali, M., et al. (2019). Genome-wide meta-analysis of depression identifies 102 independent variants and highlights the importance of the prefrontal brain regions. Nat. Neurosci. 22, 343-352. doi: 10.1038/s41593-018-0326-7

Hurd, Y. L., Suzuki, M., and Sedvall, G. C. (2001). D1 and D2 dopamine receptor mRNA expression in whole hemisphere sections of the human brain. J. Chem. Neuroanat. 22, 127-137. doi: 10.1016/s0891-0618(01)00122-3

Ishii, K., Tsuji, H., and Tamaoka, A. (2011). Mumps virus encephalitis with symmetric claustrum lesions. AJNR Am. J. Neuroradiol. 32:E139.

Jankovic, J., Chen, S., and Le, W. D. (2005). The role of Nurr1 in the development of dopaminergic neurons and Parkinson's disease. Prog. Neurobiol. 77, 128-138. doi: 10.1016/j.pneurobio.2005.09.001

Jensen, K. P. (2016). A review of genome-wide association studies of stimulant and opioid use disorders. Mol. Neuropsychiatr. 2, 37-45. doi: 10.1159/000444755

Joutsa, J., Horn, A., Hsu, J., and Fox, M. D. (2018). Localizing parkinsonism based on focal brain lesions. Brain 141, 2445-2456. doi: 10.1093/brain/awy161

Kaada, B. R., and Jasper, H. (1952). Respiratory responses to stimulation of temporal pole, insula, and hippocampal and limbic gyri in man. AMA Arch. Neurol. Psychiatry 68, 609-619. doi: 10.1002/ana.24252

Kalaitzakis, M. E., Pearce, R. K. B., and Gentleman, S. M. (2009). Clinical correlates of pathology in the claustrum in parkinson's disease and dementia with lewy bodies. Neurosci. Lett. 461, 12-15. doi: 10.1016/j.neulet.2009.05.083

Kalivas, P. W. (2009). The glutamate homeostasis hypothesis of addiction. Nat. Rev. Neurosci. 10, 561-572. doi: 10.1038/nrn2515

Kandilarova, S., Stoyanov, D., Kostianev, S., and Specht, K. (2018). Altered resting state effective connectivity of anterior insula in depression. Front. Psychiatry 9:83. doi: 10.3389/fpsyt.2018.00083

Kelly, C., Toro, R., Di Martino, A., Cox, C. L., Bellec, P., Castellanos, F. X., et al. (2012). A convergent functional architecture of the insula emerges across imaging modalities. Neuroimage 61, 1129-1142. doi: 10.1016/j.neuroimage. 2012.03.021

Knackstedt, L. A., and Kalivas, P. W. (2009). Glutamate and reinstatement. Curr. Opin. Pharmacol. 9, 59-64. doi: 10.1016/j.coph.2008.12.003

Koubeissi, M. Z., Bartolomei, F., Beltagy, A., and Picard, F. (2014). Electrical stimulation of a small brain area reversibly disrupts consciousness. Epilepsy Behav. 37, 32-35. doi: 10.1016/j.yebeh.2014.05.027

Kozlowski, P. B., Brudkowska, J., Kraszpulski, M., Sersen, E. A., Wrzolek, M. A., Anzil, A. P., et al. (1997). Microencephaly in children congenitally infected with human immunodeficiency virus-a gross-anatomical morphometric study. Acta Neuropathol. 93, 136-145. doi: 10.1007/s004010050594

Kuehn, E., Mueller, K., Lohmann, G., and Schuetz-Bosbach, S. (2016). Interoceptive awareness changes the posterior insula functional connectivity profile. Brain Struct. Funct. 221, 1555-1571. doi: 10.1007/s00429-015-0989-8

Kurada, L., Bayat, A., Joshi, S., and Koubeissi, M. Z. (2019). The claustrum in relation to seizures and electrical stimulation. Front. Neuroanat. 13:8. doi: 10. 3389/fnana.2019.00008

Kutlu, M. G., Burke, D., Slade, S., Hall, B. J., Rose, J. E., and Levin, E. D. (2013). Role of insular cortex D1 and D2 dopamine receptors in nicotine self-administration in rats. Behav. Brain Res. 256, 273-278. doi: 10.1016/j.bbr.2013.08.005

Laowattana, S., Zeger, S. L., Lima, J. A. C., Goodman, S. N., Wittstein, I. S., and Oppenheimer, S. M. (2006). Left insular stroke is associated with adverse cardiac outcome. Neurology 66, 477-483. doi: 10.1212/01.wnl.0000202684.296 40.60

Law, C.-Y., Chang, S. T.-L., Cho, S. Y., Yau, E. K.-C., Ng, G. S.-F., Fong, N.-C., et al. (2015). Clinical whole-exome sequencing reveals a novel missense pathogenic variant of GNAO1 in a patient with infantile-onset epilepsy. Clin. Chim. Acta 451, 292-296. doi: 10.1016/j.cca.2015.10.011

Le, W., Pan, T., Huang, M., Xu, P., Xie, W., Zhu, W., et al. (2008). Decreased NURR1 gene expression in patients with Parkinson's disease. J. Neurol. Sci. 273, 29-33. doi: 10.1016/j.jns.2008.06.007

Le Foll, B., and French, L. (2018). Transcriptomic characterization of the human habenula highlights drug metabolism and the neuroimmune system. Front. Neurosci. 12:742. doi: 10.3389/fnins.2018.00742

Le Foll, B., Gallo, A., Le Strat, Y., Lu, L., and Gorwood, P. (2009). Genetics of dopamine receptors and drug addiction: a comprehensive review. Behav. Pharmacol. 20, 1-17. doi: 10.1097/fbp.0b013e3283242f05

Lee, H.-Y., Tae, W. S., Yoon, H.-K., Lee, B.-T., Paik, J.-W., Son, K.-R., et al. (2011). Demonstration of decreased gray matter concentration in the midbrain encompassing the dorsal raphe nucleus and the limbic subcortical regions in major depressive disorder: an optimized voxel-based morphometry study. J. Affect. Disord. 133, 128-136. doi: 10.1016/j.jad.2011.04.006

Mathur, B. N., Caprioli, R. M., and Deutch, A. Y. (2009). Proteomic analysis illuminates a novel structural definition of the claustrum and insula. Cereb. Cortex 19, 2372-2379. doi: 10.1093/cercor/bhn253

McInnes, L., Healy, J., and Melville, J. (2018). UMAP: Uniform Manifold Approximation and Projection for Dimension Reduction. arXiv. Available at: http://arxiv.org/abs/1802.03426 (accessed October 10, 2018).

Meletti, S., Giovannini, G., d'Orsi, G., Toran, L., Monti, G., Guha, R., et al. (2017). New-onset refractory status epilepticus with claustrum damage: definition of the clinical and neuroimaging features. Front. Neurol. 8:111. doi: 10.3389/fneur. 2017.00111

Meletti, S., Slonkova, J., Mareckova, I., Monti, G., Specchio, N., Hon, P., et al. (2015). Claustrum damage and refractory status epilepticus following febrile illness. Neurology 85, 1224-1232. doi: 10.1212/WNL.0000000000001996

Mesulam, M. M., and Mufson, E. J. (1982). Insula of the old world monkey. i. Architectonics in the insulo-orbito-temporal component of the paralimbic brain. J. Comp. Neurol. 212, 1-22. doi: 10.1002/cne.902120102

Miller, J. A., Ding, S.-L., Sunkin, S. M., Smith, K. A., Ng, L., Szafer, A., et al. (2014a). Transcriptional landscape of the prenatal human brain. Nature 508, 199-206.

Miller, J. A., Menon, V., Goldy, J., Kaykas, A., Lee, C.-K., Smith, K. A., et al. (2014b). Improving reliability and absolute quantification of human brain microarray data by filtering and scaling probes using RNA-Seq. BMC Geno. 15:154. doi: 10.1186/1471-2164-15-154

Minicã, C. C., Mbarek, H., Pool, R., Dolan, C. V., Boomsma, D. I., and Vink, J. M. (2017). Pathways to smoking behaviours: biological insights from the Tobacco and Genetics Consortium meta-analysis. Mol. Psychiatry 22, 82-88. doi: $10.1038 / \mathrm{mp} .2016 .20$

Nagai, M., Hoshide, S., and Kario, K. (2010). The insular cortex and cardiovascular system: a new insight into the brain-heart axis. J. Am. Soc. Hyp. 4, 174-182. doi: 10.1016/j.jash.2010.05.001

Nakamura, K., Kodera, H., Akita, T., Shiina, M., Kato, M., Hoshino, H., et al. (2013). De Novo mutations in GNAO1, encoding a Gao subunit of heterotrimeric G proteins, cause epileptic encephalopathy. Am. J. Hum. Genet. 93, 496-505. doi: 10.1186/s13023-016-0416-0

Naqvi, N. H., and Bechara, A. (2010). The insula and drug addiction: an interoceptive view of pleasure, urges, and decision-making. Brain Struct. Funct. 214, 435-450. doi: 10.1007/s00429-010-0268-7

Naqvi, N. H., Rudrauf, D., Damasio, H., and Bechara, A. (2007). Damage to the insula disrupts addiction to cigarette smoking. Science 315, 531-534. doi: $10.1126 /$ science. 1135926

Nestler, E. J. (2005). Is there a common molecular pathway for addiction? Nat. Neurosci. 8, 1445-1449. doi: 10.1038/nn1578

Nixon, J., Bateman, D., and Moss, T. (2001). An MRI and neuropathological study of a case of fatal status epilepticus. Seizure 10, 588-591. doi: 10.1053/seiz.2001. 0553

Ogan, M. B., Toker, L., Tripathy, S. J., Li, B., Rocco, B., Sibille, E., et al. (2017). Cross-laboratory analysis of brain cell type transcriptomes with applications to interpretation of bulk tissue data. eNeuro 4, ENEURO.0212-17.2017. doi: 10.1523/ENEURO.0212-17.2017

Osorio-Gómez, D., Guzmán-Ramos, K., and Bermúdez-Rattoni, F. (2017). Memory trace reactivation and behavioral response during retrieval are differentially modulated by amygdalar glutamate receptors activity: interaction 
between amygdala and insular cortex. Learn. Mem. 24, 14-23. doi: 10.1101/lm. 042895.116

Paller, K. A., Ranganath, C., Gonsalves, B., LaBar, K. S., Parrish, T. B., Gitelman, D. R., et al. (2003). Neural correlates of person recognition. Learn. Mem. 10, 253-260. doi: 10.1101/lm.57403

Pasman, J. A., Verweij, K. J. H., Gerring, Z., Stringer, S., Sanchez-Roige, S., Treur, J. L., et al. (2018). GWAS of lifetime cannabis use reveals new risk loci, genetic overlap with psychiatric traits, and a causal influence of schizophrenia. Nat. Neurosci. 21, 1161-1170. doi: 10.1038/s41593-018-0206-1

Paulus, M. P., and Stein, M. B. (2006). An insular view of anxiety. Biol. Psychiatry 60, 383-387. doi: 10.1016/j.biopsych.2006.03.042

Paus, T., Pesaresi, M., and French, L. (2014). White matter as a transport system. Neuroscience 276, 117-125. doi: 10.1016/j.neuroscience.2014.01.055

Paxinos, G., and Watson, C. (1986). The Rat Brain in Stereotaxic Coordinates. New York, NY: Academic Press.

Peckys, D., and Landwehrmeyer, G. B. (1999). Expression of mu, kappa, and delta opioid receptor messenger RNA in the human CNS: a 33P in situ hybridization study. Neuroscience 88, 1093-1135. doi: 10.1016/s0306-4522(98)00251-6

Piñero, J., Bravo, À, Queralt-Rosinach, N., Gutiérrez-Sacristán, A., Deu-Pons, J., Centeno, E., et al. (2017). DisGeNET: a comprehensive platform integrating information on human disease-associated genes and variants. Nucleic Acids Res. 45, D833-D839. doi: 10.1093/nar/gkw943

Pirone, A., Cozzi, B., Edelstein, L., Peruffo, A., Lenzi, C., Quilici, F., et al. (2012). Topography of Gng2- and NetrinG2-expression suggests an insular origin of the human claustrum. PLoS One 7:e44745. doi: 10.1371/journal.pone.0044745

Pollatos, O., Schandry, R., Auer, D. P., and Kaufmann, C. (2007). Brain structures mediating cardiovascular arousal and interoceptive awareness. Brain Res. 1141, 178-187. doi: 10.1016/j.brainres.2007.01.026

Puelles, L. (2014). "Chapter 4 - development and evolution of the claustrum," in The Claustrum, eds J. R. Smythies, L. R. Edelstein, and V. S. Ramachandran, (San Diego, CA: Academic Press), 119-176. doi: 10.1016/b978-0-12-404566-8. 00004-0

Pushparaj, A., Hamani, C., Yu, W., Shin, D. S., Kang, B., Nobrega, J. N., et al. (2013). Electrical stimulation of the insular region attenuates nicotine-taking and nicotine-seeking behaviors. Neuropsychopharmacology 38, 690-698. doi: 10.1038/npp.2012.235

Pushparaj, A., Kim, A. S., Musiol, M., Zangen, A., Daskalakis, Z. J., Zack, M., et al. (2015). Differential involvement of the agranular vs granular insular cortex in the acquisition and performance of choice behavior in a rodent gambling task. Neuropsychopharmacology 40, 2832-2842. doi: 10.1038/npp.2015.133

Pushparaj, A., and Le Foll, B. (2015). Involvement of the caudal granular insular cortex in alcohol self-administration in rats. Behav. Brain Res. 293, 203-207. doi: 10.1016/j.bbr.2015.07.044

Qin, C., Liu, Q., Hu, Z.-W., Zhou, L.-Q., Shang, K., Bosco, D. B., et al. (2018). Microglial TLR4-dependent autophagy induces ischemic white matter damage via STAT1/6 pathway. Theranostics 8, 5434-5451. doi: 10.7150/thno.27882

Ragozzino, M. E., and Kesner, R. P. (1999). The role of the agranular insular cortex in working memory for food reward value and allocentric space in rats. Behav. Brain Res. 98, 103-112. doi: 10.1016/s0166-4328(98)00058-8

Ritchie, M. E., Phipson, B., Wu, D., Hu, Y., Law, C. W., Shi, W., et al. (2015). limma powers differential expression analyses for RNA-sequencing and microarray studies. Nucleic Acids Res. 43:e47. doi: 10.1093/nar/gkv007

Sacchetti, P., Mitchell, T. R., Granneman, J. G., and Bannon, M. J. (2001). Nurr1 enhances transcription of the human dopamine transporter gene through a novel mechanism. J. Neurochem. 76, 1565-1572. doi: 10.1046/j.1471-4159. 2001.00181.x

Sakurada, K., Ohshima-Sakurada, M., Palmer, T. D., and Gage, F. H. (1999). Nurr1, an orphan nuclear receptor, is a transcriptional activator of endogenous tyrosine hydroxylase in neural progenitor cells derived from the adult brain. Development 126, 4017-4026.

Saucedo-Cardenas, O., Quintana-Hau, J. D., Le, W. D., Smidt, M. P., Cox, J. J., De Mayo, F., et al. (1998). Nurr1 is essential for the induction of the dopaminergic phenotype and the survival of ventral mesencephalic late dopaminergic precursor neurons. Proc. Natl. Acad. Sci. U.S.A. 95, 4013-4018. doi: 10.1073/pnas.95.7.4013

Schier, L. A., Blonde, G. D., and Spector, A. C. (2016). Bilateral lesions in a specific subregion of posterior insular cortex impair conditioned taste aversion expression in rats. J. Comp. Neurol. 524, 54-73. doi: 10.1002/cne. 23822
Schmidt, H. D., and Pierce, R. C. (2010). Cocaine-induced neuroadaptations in glutamate transmission: potential therapeutic targets for craving and addiction. Ann. N. Y. Acad. Sci. 1187, 35-75. doi: 10.1111/j.1749-6632.2009.05144.x

Sevigny, J. J., Chin, S. S. M., Milewski, Y., Albers, M. W., Gordon, M. L., and Marder, K. (2005). HIV encephalitis simulating huntington's disease. Mov. Disord. 20, 610-613. doi: 10.1002/mds.20379

Showers, M. J., and Lauer, E. W. (1961). Somatovisceral motor patterns in the insula. J. Comp. Neurol. 117, 107-115. doi: 10.1002/cne.9011 70109

Sliz, D., and Hayley, S. (2012). Major depressive disorder and alterations in insular cortical activity: a review of current functional magnetic imaging research. Front. Hum. Neurosci. 6:323. doi: 10.3389/fnhum.2012.00323

Sperner, J., Sander, B., Lau, S., Krude, H., and Scheffner, D. (1996). Severe transitory encephalopathy with reversible lesions of the claustrum. Pediatr. Radiol. 26, 769-771. doi: 10.1007/bf01396197

Strand, A. D., Aragaki, A. K., Baquet, Z. C., Hodges, A., Cunningham, P., Holmans, P., et al. (2007). Conservation of regional gene expression in mouse and human brain. PLoS Genet. 3:e59. doi: 10.1371/journal.pgen.0030059

Stratmann, M., Konrad, C., Kugel, H., Krug, A., Schöning, S., Ohrmann, P., et al. (2014). Insular and hippocampal gray matter volume reductions in patients with major depressive disorder. PLoS One 9:e102692. doi: 10.1371/journal.pone. 0102692

Tasic, B., Menon, V., Nguyen, T. N., Kim, T. K., Jarsky, T., Yao, Z., et al. (2016). Adult mouse cortical cell taxonomy revealed by single cell transcriptomics. Nat. Neurosci. 19, 335-346. doi: 10.1038/nn.4216

Toker, L., Feng, M., and Pavlidis, P. (2016). Whose sample is it anyway? Widespread misannotation of samples in transcriptomics studies. F1000Res 5:2103. doi: 10.12688/f1000research.9471.1

Tong, N., Perry, S. W., Zhang, Q., James, H. J., Guo, H., Brooks, A., et al. (2000). Neuronal fractalkine expression in HIV-1 encephalitis: roles for macrophage recruitment and neuroprotection in the central nervous system. J. Immunol. 164, 1333-1339. doi: 10.4049/jimmunol.164.3.1333

Torgerson, C. M., Irimia, A., Goh, S. Y. M., and Van Horn, J. D. (2015). The DTI connectivity of the human claustrum. Hum. Brain Mapp. 36, 827-838. doi: $10.1002 / \mathrm{hbm} .22667$

Tzschentke, T. M., and Schmidt, W. J. (2003). Glutamatergic mechanisms in addiction. Mol. Psychiatry 8, 373-382. doi: 10.1038/sj.mp.4001269

Veer, I. M., Beckmann, C. F., van Tol, M.-J., Ferrarini, L., Milles, J., Veltman, D. J., et al. (2010). Whole brain resting-state analysis reveals decreased functional connectivity in major depression. Front. Syst. Neurosci. 4:41. doi: 10.3389/fnsys. 2010.00041

von Leupoldt, A., Sommer, T., Kegat, S., Baumann, H. J., Klose, H., Dahme, B., et al. (2008). The unpleasantness of perceived dyspnea is processed in the anterior insula and amygdala. Am. J. Respir. Crit. Care Med. 177, 1026-1032. doi: $10.1164 / \mathrm{rccm} .200712-18210 \mathrm{C}$

Wang, C., Wu, H., Chen, F., Xu, J., Li, H., Li, H., et al. (2018). Disrupted functional connectivity patterns of the insula subregions in drug-free major depressive disorder. J. Affect. Disord. 234, 297-304. doi: 10.1016/j.jad.2017.12.033

Wang, Q., Ng, L., Harris, J. A., Feng, D., Li, Y., Royall, J. J., et al. (2017). Organization of the connections between claustrum and cortex in the mouse. J. Comp. Neurol. 525, 1317-1346. doi: 10.1002/cne.24047

Watakabe, A., Ohsawa, S., Ichinohe, N., Rockland, K. S., and Yamamori, T. (2014). Characterization of claustral neurons by comparative gene expression profiling and dye-injection analyses. Front. Syst. Neurosci. 8:98. doi: 10.3389/fnsys.2014. 00098

Watson, C., and Puelles, L. (2017). Developmental gene expression in the mouse clarifies the organization of the claustrum and related endopiriform nuclei. J. Comp. Neurol. 525, 1499-1508. doi: 10.1002/cne.24034

Weiner, J. III, and Domaszewska, T. (2016). tmod: an R package for general and multivariate enrichment analysis. PeerJ Preprints 4:e2420v1. doi: 10.7287/peerj. preprints.2420v1

Wisner, K. M., Patzelt, E. H., Lim, K. O., and MacDonald, A. W. III (2013). An intrinsic connectivity network approach to insula-derived dysfunctions among cocaine users. Am. J. Drug Alcohol. Abuse 39, 403-413. doi: 10.3109/00952990. 2013.848211

Wray, N. R., Ripke, S., Mattheisen, M., Trzaskowski, M., Byrne, E. M., Abdellaoui, A., et al. (2018). Genome-wide association analyses identify 44 risk variants and refine the genetic architecture of major depression. Nat. Genet. 50, 668-681. doi: 10.1038/s41588-018-0090-3 
Xing, G., Zhang, L., Russell, S., and Post, R. (2006). Reduction of dopaminerelated transcription factors Nurr1 and NGFI-B in the prefrontal cortex in schizophrenia and bipolar disorders. Schizophr. Res. 84, 36-56. doi: 10.1016/ j.schres.2005.11.006

Yiannakas, A., and Rosenblum, K. (2017). The insula and taste learning. Front. Mol. Neurosci. 10:335. doi: 10.3389/fnmol.2017.00335

Yin, B., Terhune, D. B., Smythies, J., and Meck, W. H. (2016). Claustrum, consciousness, and time perception. Curr. Opin. Behav. Sci. 8, 258-267. doi: 10.1016/j.cobeha.2016.02.032

Zaki, J., Davis, J. I., and Ochsner, K. N. (2012). Overlapping activity in anterior insula during interoception and emotional experience. Neuroimage 62, 493499. doi: 10.1016/j.neuroimage.2012.05.012

Zetterström, R. H., Solomin, L., Jansson, L., Hoffer, B. J., Olson, L., and Perlmann, T. (1997). Dopamine neuron agenesis in Nurr1-deficient mice. Science 276, 248-250. doi: $10.1126 /$ science. 276.5310 .248
Zhang, L., Le, W., Xie, W., and Dani, J. A. (2012). Age-related changes in dopamine signaling in Nurr1 deficient mice as a model of Parkinson's disease. Neurobiol. Aging 33:e7-16. doi: 10.1016/j.neurobiolaging.2011. 03.022

Conflict of Interest: The authors declare that the research was conducted in the absence of any commercial or financial relationships that could be construed as a potential conflict of interest.

Copyright (c) 2019 Ibrahim, Le Foll and French. This is an open-access article distributed under the terms of the Creative Commons Attribution License (CC BY).

The use, distribution or reproduction in other forums is permitted, provided the original author(s) and the copyright owner(s) are credited and that the original publication in this journal is cited, in accordance with accepted academic practice. No use, distribution or reproduction is permitted which does not comply with these terms. 